\title{
Silencing of lysyl oxidase-like 2 inhibits the migration, invasion and epithelial-to-mesenchymal transition of renal cell carcinoma cells through the Src/FAK signaling pathway
}

\author{
XI HONG ${ }^{1}$ and JIAN-JUN YU ${ }^{1,2}$ \\ ${ }^{1}$ Department of Urology, Shanghai Jiao Tong University Affiliated Sixth People's Hospital, Shanghai 200233; ${ }^{2}$ Department \\ of Urology, Shanghai Jiao Tong University Affiliated Sixth People's Hospital South Campus, Shanghai 201499, P.R. China
}

Received December 12, 2017; Accepted October 22, 2018

DOI: $10.3892 /$ ijo.2019.4726

\begin{abstract}
The aim of the present study was to investigate the effects of lysyl oxidase-like 2 (LOXL2) on the invasion, migration and epithelial-to-mesenchymal transition (EMT) of renal cell carcinoma (RCC) cells through the steroid receptor coactivator ( $\mathrm{Src}$ )/focal adhesion kinase (FAK) signaling pathway. RCC tissues and adjacent normal tissues were collected from 80 patients with RCC. Immunohistochemistry was used to determine the positive expression rate of the LOXL2 protein. The expression levels of LOXL2 in the HK-2, 786-O, ACHN, Caki1 and A498 cell lines were detected by reverse transcription-quantitative polymerase chain reaction (RT-qPCR). The high LOXL2-expressing 786-O cells were selected for gene silencing experiments, whereas Cakil cells, which exhibited low LOXL2 expression, were used for overexpression experiments. RT-qPCR and western blot analysis were applied to determine the expression of LOXL2, FAK, Src, matrix metalloproteinase (MMP)-9, epithelial (E)-cadherin, neuronal (N)-cadherin and vimentin. A MTT assay, a Transwell assay, a wound healing assay and flow cytometry were performed to detect cell proliferation, invasion, migration, cell cycle distribution and apoptosis, respectively. The protein expression rate of LOXL2 in RCC tissues was higher compared with that in adjacent normal tissues. Compared with adjacent normal tissues, the mRNA and protein expression levels of LOXL2, FAK, Src, MMP-9, N-cadherin and vimentin and the levels of FAK and Src phosphorylation were increased, while the mRNA and protein expression levels of E-cadherin were decreased in RCC tissues. Following the transfection of 786-O cells with small interfering (si) RNA against LOXL2, the mRNA and
\end{abstract}

Correspondence to: Dr Jian-Jun Yu, Department of Urology, Shanghai Jiao Tong University Affiliated Sixth People's Hospital, 600 Yishan Road, Shanghai 200233, P.R. China

E-mail: yujj917@163.com

Key words: lysyl oxidase-like 2, steroid receptor coactivator/ focal adhesion kinase signaling pathway, renal cell carcinoma, epithelial-to-mesenchymal transition, invasion, migration protein expression levels of FAK, Src, MMP-9, N-cadherin and vimentin and the levels of phosphorylated FAK and Src were notably decreased in the si-LOXL2 and PP2 inhibitor treated groups, while that of E-cadherin was substantially increased. Additionally, cell proliferation, invasion, migration and the percentage of RCC cells in the G1 phase were reduced, and cell apoptosis was increased. Additionally, Cakil cells transfected with LOXL2 exhibited an opposite trend. In summary, these results indicate that LOXL2 silencing inhibits the invasion, migration and EMT in RCC cells through inhibition of the Src/FAK signaling pathway.

\section{Introduction}

Renal cell carcinoma (RCC) is a complex disease entity comprising different types of cancer occurring in the kidney, each of which results from a different gene, with different histological characteristics and a clinical course that responds differently to therapy (1). Over the past two decades, the incidence of RCC has increased due to an increasing number of patients diagnosed with small kidney tumor types (2). The overall lifetime risk for RCC development is $\sim 1$ in 67 , and it is higher in men compared with women (3). Due to its gradual onset and progression, RCC may be difficult to detect and $\sim 80 \%$ of renal tumor types are discovered incidentally during unassociated abdominal imaging examinations (4). Among all RCCs, clear cell RCC is the most frequently occurring type, accounting for $>90 \%$ of all cases (5). The risk factors for RCC may vary, including smoking, obesity, hypertension, dietary habits and living environment (6). Diverse treatments for RCC have been reported, including the use of drugs, virus-based gene therapies and ablative therapies, in addition to preoperative tumor embolization (7-10). However, novel therapies are required due to the complexity and poor prognosis of RCC.

The lysyl oxidase-like 2 (LOXL2) protein is a type of human paralogue of lysyl oxidase (LOX) that functions as an amine oxidase and aids the formation of lysine-derived cross-links in collagen and elastin (11). At present, LOXL2 is considered to be responsible for a diverse range of cellular functions, including cell adhesion, migration and invasion, metastasis, epithelial-to-mesenchymal transition (EMT) and malignant transformation (12). Downregulated LOXL2 expression is 
reported to inhibit cell migration and invasion in RCC (13). The steroid receptor coactivator (Src)/focal adhesion kinase (FAK) signaling pathway is known to be involved in the migration and invasion of various tumor cell types (14). A previous study reported that the inhibition of Src may represent a promising option for the treatment of RCC (15). Accumulating evidence indicates a potential association between LOXL2 and the Src/FAK signaling pathway, as tumor-secreted LOXL2 is able to activate fibroblasts throughFAK signaling, andLOXL2 is capable of activating the FAK/protein kinase B (AKT)/mammalian target of rapamycin signaling pathways $(16,17)$. However, few studies investigating LOXL2 and the Src-AKT signaling pathway in RCC have been conducted to date. Therefore, the aim of the present study was to investigate the effect of LOXL2 on the invasion, migration and EMT of RCC cells through the Src/FAK signaling pathway, in order to identify novel potential targets for the treatment of RCC.

\section{Materials and methods}

Ethics statement. The study protocol was approved by the Ethics Committee of Shanghai Jiao Tong University Affiliated Sixth People's Hospital (Shanghai, China) and Shanghai Jiao Tong University Affiliated Sixth People's Hospital South Campus (Shanghai, China), and all the patients signed informed consent forms. The present study obtained the approval of the Ethics Review Committee of Shanghai Jiao Tong University Affiliated Sixth People's Hospital and Shanghai Jiao Tong University Affiliated Sixth People's Hospital South Campus (approval no. 201407004).

Study subjects. RCC tissues and adjacent normal tissues were collected from 80 patients with RCC, including 46 men and 30 women, who were hospitalized at the Shanghai Jiao Tong University Affiliated Sixth People's Hospital and Shanghai Jiao Tong University Affiliated Sixth People's Hospital South Campus between September 2014 and March 2017. The age of the patients ranged from 14 to 61 years, with a mean of 50.99 years. Among the patients, 25 were aged $<50$ years and 55 were aged $\geq 55$ years. According to the pathological diagnosis and classification criteria for RCC published by the World Health Organization, 38 cases were diagnosed as Fuhrman grade I-II and 42 cases as III-IV (18), 42 cases were diagnosed as Tumor-Node-Metastasis (TNM) stage pT1-pT2 and 38 cases as pT3-pT4 (19); in addition, 36 cases had a tumor diameter of $<4 \mathrm{~cm}$ and 44 had a tumor diameter of $\geq 4 \mathrm{~cm}$. None of the patients had been subjected to radiotherapy or chemotherapy.

Hematoxylin and eosin $(H \& E)$ staining. The tissue specimens were fixed in $10 \%$ neutral formaldehyde for $16-18 \mathrm{~h}$ at room temperature, dehydrated through graded ethanol $(50,70,80$, 90 and $100 \%$ ), transparentized in xylene at $35^{\circ} \mathrm{C}$ for $30 \mathrm{~min}$ and embedded in paraffin at $60^{\circ} \mathrm{C}$ for $30 \mathrm{~min}$. Subsequently, the specimens were sliced into serial sections at a thickness of $5 \mu \mathrm{m}$ and allowed to stand at $45^{\circ} \mathrm{C}$. Next, the sections were extracted, baked at $60^{\circ} \mathrm{C}$ for $1 \mathrm{~h}$, deparaffinized by washing with xylene and rehydrated. Then, H\&E staining was performed at a temperature of $35^{\circ} \mathrm{C}$ as follows: the sections were stained by hematoxylin for $10 \mathrm{~min}$, washed with water for $15 \mathrm{~min}$, differentiated with $1 \%$ hydrochloric acid-ethanol for $3 \mathrm{sec}$, washed with water for $10 \mathrm{sec}$ and stained with $0.5 \%$ eosin for 3 min (Beijing Solarbio Science \& Technology Co., Ltd., Beijing, China). Then, the sections were dehydrated with graded ethanol, transparentized with xylene and sealed with neutral gum. The pathological changes of the RCC tissues and adjacent normal tissues were observed under an optical microscope (magnification, x200) (CX31-LV320; Olympus Corporation, Tokyo, Japan).

Immunohistochemistry. The tissues were embedded in paraffin and sliced into 3-4- $\mu \mathrm{m}$ sections. The sections were deparaffinized and hydrated at room temperature for $20 \mathrm{~min}$. Subsequently, the endogenous peroxidase activity was blocked in $3 \% \mathrm{H}_{2} \mathrm{O}_{2}$ at room temperature for $10 \mathrm{~min}$ while the sections were processed for antigen retrieval in a microwave at a power of $800 \mathrm{~W}$ at $90^{\circ} \mathrm{C}$ for $5 \mathrm{~min}$. Next, the sections were blocked with $10 \%$ goat serum and incubated at room temperature for $10 \mathrm{~min}$. Primary polyclonal rabbit anti-human LOXL2 antibody (1:100; cat no. ab179810; Abcam, Cambridge, MA, USA) was added to the sections and left overnight at $4{ }^{\circ} \mathrm{C}$. Secondary biotinylated goat anti-rabbit immunoglobulin $\mathrm{G}$ (IgG) antibody (1:1,000; cat no. ab6789; Abcam) was added to the sections for $30 \mathrm{~min}$ at $37^{\circ} \mathrm{C}$. Next, hematoxylin (cat no. C0105. Beyotime Institute of Biotechnology, Shanghai, China) was used to counterstain the nuclei for $30 \mathrm{sec}$ at $37^{\circ} \mathrm{C}$, followed by 3,3'-diaminobenzidine (cat no. P0202; Beyotime Institute of Biotechnology) staining at $37^{\circ} \mathrm{C}$ for $10 \mathrm{~min}$. Subsequently, the sections were dehydrated with hydrochloric acid ethanol to clear and sealed with gum. Images were captured under an optical microscope (magnification, x200) (Olympus Corporation), and analyzed using Image-Pro Plus 6.0 software (Media Cybernetics, Inc., Rockville, MD, USA). Brown-yellow cytoplasmic staining was classified as a positive expression.

Reverse transcription-quantitative polymerase chain reaction $(R T-q P C R)$. Frozen tissues $(100 \mathrm{mg})$ were obtained and a TRIzol $^{\circledR}$ kit (cat no. 16096020; Thermo Fisher Scientific, Inc., Waltham, MA, USA) was employed to extract total RNA, according to the manufacturer's protocol. The primers were designed by the biological software packages Primer Premier 5 (Premier Biosoft International, Palo Alto, CA, USA) and Oligo 6.0 software (Molecular Biology Insights Inc., Cascade, CO, USA) and synthesized by Takara Biotechnology Co., Ltd. (Dalian, China), and are presented in Table I. RNA $(10 \mu \mathrm{l})$ was extracted and diluted by RNase-free ultra-pure water (x20). The optical density (OD) at $260 \mathrm{~nm}$ and $280 \mathrm{~nm}$ was recorded with an ultraviolet/visible spectrophotometer, and the concentration and purity of the total RNA were measured. Next, $5 \mu 1$ Mix reagent (cat no. 4368702; Tideradar Beijing Technology Co., Ltd., Beijing, China), $5 \mu$ l total RNA and $10 \mu \mathrm{l}$ RNase-free $\mathrm{H}_{2} \mathrm{O}$ were added into an Eppendorf tube, mixed by centrifugation $\left(7,200 \mathrm{xg}\right.$ at $4^{\circ} \mathrm{C}$ for $\left.1 \mathrm{~min}\right)$ and placed in a $\mathrm{qPCR}$ instrument. The reaction conditions were as follows: $37^{\circ} \mathrm{C}$ for $15 \mathrm{~min}$ and $85^{\circ} \mathrm{C}$ for $5 \mathrm{sec}$; and the reaction was terminated at $4^{\circ} \mathrm{C}$. The cDNA obtained by RT was stored at $-20^{\circ} \mathrm{C}$. The ABI7500 qPCR instrument (ABI 7500; Applied Biosystems; Thermo Fisher Scientific, Inc.) was used for RT-qPCR and the reaction conditions were as follows: Pre-denaturation at $95^{\circ} \mathrm{C}$ for $10 \mathrm{~min}$ and a total of 40 cycles of denaturation at $95^{\circ} \mathrm{C}$ for 
Table I. Primer sequences of associated genes for reverse transcription-quantitative polymerase chain reaction.

\begin{tabular}{ll}
\hline Gene & \multicolumn{1}{c}{ Sequence } \\
\hline LOXL2 & F: 5'-GGGTGGAGGTGTACTATGATGG-3' \\
& R: 5'-CTTGCCGTAGGAGGAGCTG-3' \\
FAK & F: 5'-GCTTACCTTGACCCCAACTTG-3' \\
& R: 5'-ACGTTCCATACCAGTACCCAG-3' \\
Src & F: 5'-GAGCGGCTCCAGATTGTCAA-3' \\
& R: 5'-CTGGGGATGTAGCCTGTCTGT-3' \\
MMP-9 & F: 5'-TGTACCGCTATGGTTACACTCG-3' \\
& R: 5'-GGCAGGGACAGTTGCTTCT-3' \\
E-cadherin & F: 5'-GGAAGTCAGTTCAGACTCCAGCC-3' \\
& R: 5'-AGGCCTTTTGACTGTAATCACACC-3' \\
N-cadherin & F: 5'-AACCCTTATTTTGCCCCCAAT-3' \\
& R:5'-AAGGTCATTAAACAACTTCTGAGC-3' \\
Vimentin & F: 5'-GACGCCATCAACACCGAGTT-3' \\
& R: 5'-CTTTGTCGTTGGTTAGCTGGT-3' \\
GAPDH & F: 5'-GGTGAAGGTCGGAGTCAACGG-3' \\
& R: 5'-CCTGGAAGATGGTGATGGGATT-3'
\end{tabular}

LOXL2, lysyl oxidase-like 2; FAK, focal adhesion kinase; MMP-9, matrix metalloproteinase-9; N-cadherin, neuronal cadherin; E-cadherin, epithelial cadherin; F, forward; R, reverse.

Table II. Silencing sequences.

\begin{tabular}{lc}
\hline Expression vector & Target sequences \\
\hline siRNA-LOXL2-1 & CCTDTTCCAGGTTGTTATT \\
siRNA-LOXL2-2 & CCGATTACTCCAACAACAT \\
siRNA-LOXL2-3 & CCAGATAGAGAACCTGAAT \\
siRNA-NC & TTTATAGAGGTTGTACTCC \\
\hline
\end{tabular}

siRNA, small interfering RNA; LOXL2, lysyl oxidase-like 2; NC, negative control.

$10 \mathrm{sec}$, annealing at $60^{\circ} \mathrm{C}$ for $20 \mathrm{sec}$ and extension at $72^{\circ} \mathrm{C}$ for 34 sec. SYBR Green fluorescence dye (Takara Biotechnology Co., Ltd.) was applied for RT-qPCR, which was also suitable for cell detection at $48 \mathrm{~h}$ of transfection. The expression levels were evaluation by $2^{-\Delta \Delta C q}$ method (20).

Western blot analysis. The RCC tissues and adjacent normal tissues were added to liquid nitrogen and ground into a homogeneous fine powder. Protein lysate was added (cat no. C0481; Sigma-Aldrich; Merck KGaA, Darmstadt, Germany) to the tissues at $4^{\circ} \mathrm{C}$ for $30 \mathrm{~min}$ and centrifugation was conducted at $29,000 \mathrm{x}$ g at $4^{\circ} \mathrm{C}$ for $20 \mathrm{~min}$. Next, the supernatant was collected and packaged separately for further use. The bicinchoninic acid method was used to measure the protein concentration of each sample and deionized water was used for adjustment, in order to maintain consistency with the volume of the loading sample. Subsequently, proteins were separated by SDS-PAGE (10\% gels). The sample was mixed with the loading buffer and boiled at $100^{\circ} \mathrm{C}$ for $5 \mathrm{~min}$, then the denatured protein was preserved at $-70^{\circ} \mathrm{C}$. The protein sample (50 $\mu \mathrm{g} /$ lane) was subjected to electrophoretic separation and the protein was transferred to a nitrocellulose membrane and sealed using $5 \%$ skimmed milk powder at $4^{\circ} \mathrm{C}$ overnight. Diluted primary antibodies [rabbit anti-human LOXL2, FAK, phosphorylated (p)-FAK, Src, p-Src, matrix metalloproteinase (MMP)-9, epithelial (E)-cadherin, neuronal (N)-cadherin and vimentin (1:1,000; cat nos. ab179810, ab40794, ab81298, ab47405, ab40660, ab73734, ab1416, ab18203 and ab92547, respectively; Abcam) and rabbit anti-human GAPDH (1:2,000; cat no. ab8226; Abcam) were added to the samples, incubated at room temperature for $1 \mathrm{~h}$ and washed with phosphate-buffered saline (PBS) three times, for 5 min each time. Secondary goat anti-rabbit IgG antibody (1:1,000; cat no. ab6721; Abcam) was added, incubated at room temperature for $1 \mathrm{~h}$ and washed with PBS at room temperature three times, for $5 \mathrm{~min}$ each time. Immunoreactive bands were visualized by enhanced chemiluminescence (Pierce; Thermo Fisher Scientific, Inc.) at room temperature for $1 \mathrm{~min}$. Next, the liquid was removed and the membrane was covered with a plastic wrap, photographed by X-ray and observed. Densiometric analysis was performed using Image J software (version 1.37; National Institutes of Health, Bethesda, MD, USA). GAPDH was used as the internal reference. The ratio of the gray value of the target band to that of the internal reference band was used as the relative protein expression.

Adenovirus expression vector construction and screening. The RNA interference technique was applied and the specific target sequences of small interfering RNA (siRNA) of LOXL2 were designed according to the mRNA sequence of nucleotide LOXL2 from the National Center for Biotechnology Information (NCBI; https://www.ncbi.nlm.nih. gov/). Adenovirus expression vectors targeting LOXL2 were constructed, including vectors expressing siRNA-LOXL2-1, siRNA-LOXL2-2 and siRNA-LOXL2-3 (Table II), LOXL2 overexpression adenovirus vector Ad-CMV-LOXL2-eGFP and blank adenovirus vector Ad-CMV-eGFP (Beijing Shengke Boyuan Biotechnology Co., Ltd., Beijing, China). The vector with the highest silencing efficiency was screened for subsequent cell experiments. The plasmid pLenR-GPH vector (Engreen Biosystem New Zealand Ltd., Auckland, New Zealand) was used to construct the siRNA adenovirus expression vector siRNA-LOXL2, the LOXL2 overexpression adenovirus vector Ad-CMV-LOXL2-eGFP and the blank adenovirus vector Ad-CMV-eGFP. Double-stranded DNA oligo containing interference sequence was synthesized and directly linked to the vectors digested by the restriction endonucleases NheI and KpnI. The ligation product was transformed into $E$. coli $\mathrm{DH} 5 \alpha$ cells with the purposes of amplifying plasmid, and then plasmid was extracted and identified through restriction endonucleases NheI and KpnI digestion.

Cell grouping and transfection. HK-2 (normal renal tubular epithelial cells; cat no. CRL-2190; American Type Culture Collection, Manassas, VA, USA) and the RCC cell lines 
786-0, ACHN, Cakil and A498 (Cell Resource Centre, Institute of Basic Medical Sciences, Peking Union Medical College, Beijing, China) were cultured in RPMI-1640 culture medium (cat no. 22400089; Gibco; Thermo Fisher Scientific, Inc.) containing $10 \%$ fetal bovine serum (FBS; Gibco; Thermo Fisher Scientific, Inc.). The cells were seeded into a 6 -well plate $\left(1 \times 10^{5} /\right.$ well $)$ at $37^{\circ} \mathrm{C}$ in a humidified atmosphere containing $5 \% \mathrm{CO}_{2}$. The culture medium was changed every 2-3 days. The cells were subcultured until they reached $80-90 \%$ confluence. The culture medium was then removed and the cells were washed with PBS twice, digested with $0.25 \%$ trypsin for $2-5 \mathrm{~min}$ at $37^{\circ} \mathrm{C}$, resuspended and subcultured in $5 \mathrm{ml}$ RPMI-1640 containing $10 \%$ FBS.

Cells in the logarithmic growth phase were extracted and assigned into the following groups: i) 786-O cell line, blank group (no transfection), siRNA negative control (si-NC) group (cells transfected with si-NC) and si-LOXL2 group (cells transfected with si-LOXL2); ii) Cakil cell line, blank group (no transfection), LOXL2 empty vector group (cells transfected with the empty adenovirus vector Ad-CMV-eGFP), LOXL2 vector group (cells transfected with Ad-CMV-LOXL2-eGFP), PP2 group [cells transfected with $20 \mu \mathrm{mol} / \mathrm{l}$ of the signaling pathway inhibitor PP2 (Selleck Chemicals, Houston, TX, USA)] and the LOXL2 vector+PP2 group(cellstransfectedwithAd-CMV-LOXL2-eGFP and $20 \mu \mathrm{mol} / 1 \mathrm{PP} 2)$. Prior to transfection, the cells were passaged and seeded into a 6 -well plate $\left(1 \times 10^{5} /\right.$ well). The cell confluence reached $70-80 \%$ on the day of transfection. The cells were transfected using Lipofectamine ${ }^{\circledR} 2000$ (Invitrogen; Thermo Fisher Scientific, Inc.) according to the manufacturer's protocol. Subsequently, $250 \mu 1$ serum-free Opti-MEM (Gibco; Thermo Fisher Scientific, Inc.) was used to dilute $100 \mathrm{pmol}$ blank adenovirus vector Ad-CMV-eGFP, siRNA-LOXL2 and Ad-CMV-LOXL2-eGFP solutions (final concentration, $50 \mathrm{nM}$ ), which were gently mixed and incubated at room temperature for $5 \mathrm{~min}$. Next, $250 \mu \mathrm{l}$ serum-free Opti-MEM was used to dilute $5 \mu$ l Lipofectamine 2000 and the two solutions were mixed and incubated at room temperature for $5 \mathrm{~min}$. Subsequent to combining the two mixtures, the solution was incubated at room temperature for $20 \mathrm{~min}$ and added into the wells of a cell culture plate. The transfected cells were then cultured in an incubator at $37^{\circ} \mathrm{C}$ in a humidified atmosphere containing $5 \% \mathrm{CO}_{2}$. After 6-8 h of culture, cells were resuspended in complete medium. The eGFP protein expression in the cells was observed under a fluorescence microscope (magnification, x100) (M30C; Shanghai Wan Heng Precision Instrument Co., Ltd., Shanghai, China) after a 24-h culture; two random fields were selected for image capture and the mean value was calculated. The transfection efficiency was equal to the ratio of the number of transfected cells to that of total cells. After 24-48-h culturing, the cells were used for further experiments.

MTT assay. Following transfection for $24 \mathrm{~h}$, RCC cells in the logarithmic growth phase were collected and RPMI-1640 containing $10 \%$ FBS was used to prepare the cell suspension $\left(2.5 \times 10^{5} / \mathrm{ml}\right)$. The cells were seeded into a 96-well plate, and 8 -wells were set for each group (100 $\mu \mathrm{l} /$ well); the plate was then incubated at $37^{\circ} \mathrm{C}$ in a humidified atmosphere containing $5 \% \mathrm{CO}_{2}$ for 24,48 and $72 \mathrm{~h}$. Next, $10 \mu \mathrm{l}$ MTT solution (5 mg/ml; Sigma-Aldrich; Merck KGaA) was added to each well for another 4-h culture. Once the culture was terminated, the supernatant was discarded and $150 \mu \mathrm{l}$ dimethyl sulfoxide solution was added to the plate and vibrated for $10 \mathrm{~min}$ to dissolve crystals at room temperature. A microplate reader (Bio-Rad Laboratories, Inc., Hercules, CA, USA) was used to measure the optical density (OD) value of each well at $490 \mathrm{~nm}$. Three parallel wells were set for each group and the mean value was calculated. The experiment was repeated three times. The curve of cell proliferation was drawn with time as the abscissa and the OD value as the ordinate.

Transwell assay. The RCC cells were dissolved with Matrigel (cat no. 356234; BD Biosciences, San Jose, CA, USA) overnight, and diluted with serum-free DMEM (Gibco; Thermo Fisher Scientific, Inc.) at dilution ratio of 1:3. Next, $50 \mu \mathrm{l}$ diluted Matrigel was added into the upper Transwell chamber and allowed to stand in an incubator for $30 \mathrm{~min}$ at $37^{\circ} \mathrm{C}$. The upper chamber (with serum-free medium) was inoculated with a $\sim 1 \times 10^{5} / \mathrm{ml}$ cell suspension and the DMEM medium containing $10 \%$ FBS was added to the basolateral Transwell chamber. After a $24-\mathrm{h}$ culture at $37^{\circ} \mathrm{C}$, the chambers were washed twice with PBS. Cells were removed from the top of the membranes with a cotton swab. Invading cells were fixed with $5 \%$ glutaraldehyde at $4^{\circ} \mathrm{C}$ for $30 \mathrm{~min}$ and stained with $0.1 \%$ crystal violet (Sigma-Aldrich; Merck KGaA) at $37^{\circ} \mathrm{C}$ for $10 \mathrm{~min}$. The number of invading cells was counted and used as the indicator to evaluate cell invasion and migration ability. Images were captured under an optical microscope (magnification, x200; Olympus Corporation). The experiment was repeated three times.

Wound healing assay. The RCC cells were seeded in a 6-well plate. Serum-free DMEM was used following cell attachment. When the cell confluence reached $90-100 \%$, a pipette tip $(10 \mu \mathrm{l})$ was used to scratch the 6-well plate perpendicular to the bottom of the plate, with 4-5 lines per well, ensuring that the width of all scratches was uniform. Once the cells were rinsed using PBS three times, the scratched cells were removed and cultured in an incubator. Migration distance at the scratch region was determined under an optical microscope (magnification, $\mathrm{x} 100$ ) at 0 and $24 \mathrm{~h}$, and six horizontal lines were randomly drawn and then photographed. The scratch gap confluence rate was calculated as follows: Gap confluence rate $=($ gap width at $0 \mathrm{~h}$ - gap width at $24 \mathrm{~h}$ )/gap width at $0 \mathrm{~h}$. Three duplicated wells were set in each well and the experiment was repeated three times.

Flow cytometry. The culture medium was discarded $48 \mathrm{~h}$ after transfection. A total of $1 \times 10^{5} / \mathrm{ml}$ RCC cells were then washed once with PBS balanced salt solution and digested using $0.25 \%$ trypsin. When the cells acquired a round shape, trypsin was removed and the DMEM medium containing $10 \%$ FBS was added to the cells to terminate digestion. Next, the cells were mixed to prepare a mixed cell suspension, which was centrifuged at $200 \mathrm{x}$ g for $5 \mathrm{~min}$ at $4^{\circ} \mathrm{C}$, and then the supernatant was discarded. PBS balanced salt solution was used to wash the cells twice and precooled $70 \%$ ethanol was used to fix the cells for $30 \mathrm{~min}$ at $4^{\circ} \mathrm{C}$, following which the cells were collected by centrifugation at $200 \mathrm{x} g$ for $5 \mathrm{~min}$ at $4^{\circ} \mathrm{C}$. Subsequently, PBS solution was added to wash the cells twice, and $1 \mathrm{ml}$ propidium iodide (PI) with RNAse was 


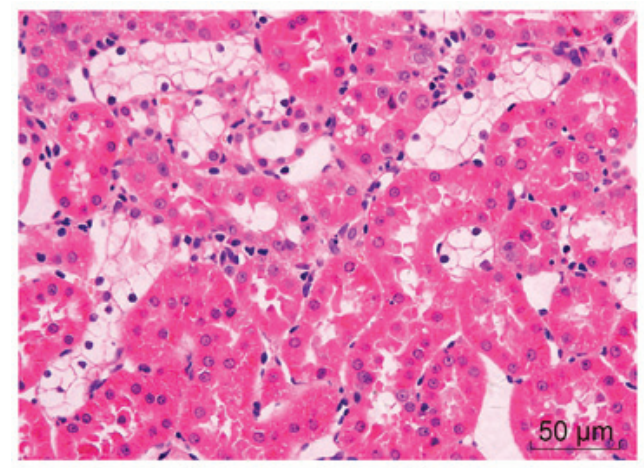

Paracancerous tissue

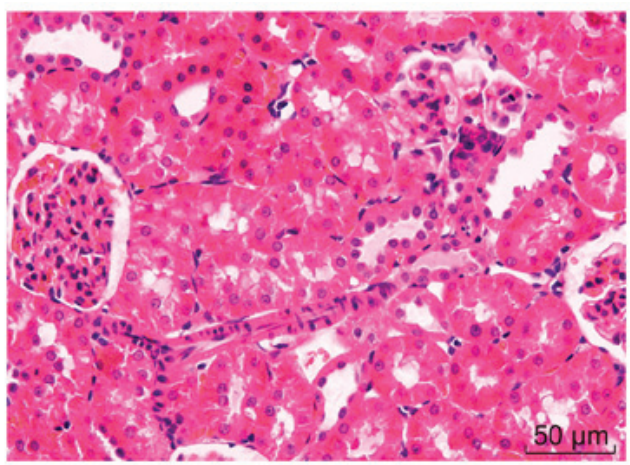

Renal carcinoma tissue

Figure 1. Hematoxylin and eosin staining. Cells exhibited dedifferentiated morphology and a disorderly arrangement in renal cell carcinoma tissues compared with normal adjacent tissues (magnification, x200; bar, $50 \mu \mathrm{m}$ ).

used for staining for $30 \mathrm{~min}$ at $37^{\circ} \mathrm{C}$. The cells were washed with PBS balanced salt solution twice and PI was removed. The volume of the mixture solution was adjusted to $1 \mathrm{ml}$ with the addition of PBS solution. The samples were transferred to a flow cytometry instrument (BD-Aria; FACS Calibur; Beckman Coulter, Miami, FL, USA) in order to record cell cycle at the activating wavelength of $488 \mathrm{~nm}$ detected by red fluorescence. Three samples were set in each group and the experiment was repeated three times.

At $48 \mathrm{~h}$ after transfection, trypsin without ethylenediaminetetraacetic acid was applied to digest the cells for $5 \mathrm{~min}$ at $37^{\circ} \mathrm{C}$, and the cells were then collected into a flow tube. Next, centrifugation was performed and the supernatant was removed. The cells were washed with cold PBS three times, followed by centrifugation at $200 \mathrm{x} \mathrm{g}$ for $5 \mathrm{~min}$ at $4^{\circ} \mathrm{C}$ and supernatant removal. Subsequently, Annexin V-fluorescein isothiocyanate (FITC) dye solution was prepared by Annexin V-FITC, PI and HEPES buffer solution at 1:2:50 using the Annexin-V-FITC apoptosis detection kit (cat no. C1065; Beyotime Institute of Biotechnology) according to the manufacturer's protocol. A total of $100 \mu \mathrm{l}$ dye solution was added to $1 \times 10^{6}$ cells for resuspension. Following oscillation and mixing, the cells were incubated at room temperature for $15 \mathrm{~min}$, followed by the addition of $1 \mathrm{ml}$ HEPES buffer solution and oscillation. The samples were transferred on flow cytometry instrument (BD-Aria), then, bandpass filters of 525 and $620 \mathrm{~nm}$ were activated by $488 \mathrm{~nm}$ wavelength to detect FITC and PI fluorescence, in addition to cell apoptosis. Three samples were set for each group and the experiment was repeated three times.

Statistical analysis. All data were processed using SPSS 21.0 statistical software (IBM Corp., Armonk, NY, USA). The measurement data were subject to normal distribution, which was expressed as the mean \pm standard deviation. The comparison of RCC and normal adjacent tissues was performed using a paired Student's t-test; the comparison between two groups was performed by an independent samples t-test and that among multiple groups by one-way analysis of variance. Tukey's post hoc test was used following analysis of variance. Numerical data were expressed as percentage or rate and analyzed using a $\chi^{2}$ test. $\mathrm{P}<0.05$ was considered to indicate statistically significant differences.

\section{Results}

Histopathological examination of RCC tissues and adjacent normal tissues. H\&E staining was performed to observe histopathological changes. In the adjacent normal tissues, the cells exhibited normal morphology and uniform arrangement, without inflammatory infiltration. In the RCC tissues, however, the cells exhibited dedifferentiated morphology and disorderly arrangement; notable tumor cell infiltration was detected, around which normal kidney tissues were observed (Fig. 1). In conclusion, the cells exhibited dedifferentiated morphology and were arranged in a disorderly manner in RCC tissues compared with adjacent normal tissues.

LOXL2 protein expression is high in RCC tissues. In order to measure the cell protein expression of LOXL2, immunohistochemistry was performed. The results (Fig. 2) revealed that LOXL2-positive cells were located in the cytoplasm, presenting as brown-yellow granules. The protein expression rate of LOXL2 in the RCC tissues was 72.5\% (58/80), which was significantly higher compared with $17.5 \%$ $(14 / 80)$ in adjacent normal tissues $(\mathrm{P}<0.05)$. Taken together, these results demonstrated that LOXL2 protein expression was higher in RCC tissues compared with that in adjacent normal tissues.

Associations between LOXL2 expression and clinicopathological characteristics of RCC. The associations between LOXL2 expression and the clinicopathological characteristics of RCC is presented in Table III. LOXL2 expression was independent of the sex and age of patients with RCC, but was significantly associated with stage [Fuhrman $(\mathrm{P}=0.001)$ and TNM $(\mathrm{P}=0.009)]$, histological type $(\mathrm{P}=0.001)$, diameter $(\mathrm{P}=0.001)$ and venous invasion $(\mathrm{P}=0.002)$. The expression of LOXL2 was significantly elevated in patients with Fuhrman grade III + IV and those with clear cell RCC with a tumor diameter $\geq 4 \mathrm{~cm}$ (all $\mathrm{P}<0.05$ ). Therefore, LOXL2 expression was significantly associated with tumor grade, type, diameter and venous invasion in RCC.

LOXL2 and FAK/Src signaling pathway genes are highly expressed and EMT-associated gene expression is affected 
Table III. Association between LOXL2 expression and clinicopathological characteristics of renal cell carcinoma.

\begin{tabular}{|c|c|c|c|c|}
\hline \multirow[b]{2}{*}{ Characteristics } & \multirow[b]{2}{*}{ Case number (n) } & \multicolumn{2}{|c|}{ LOXL2 expression } & \multirow[b]{2}{*}{ P-value } \\
\hline & & Positive & Negative & \\
\hline Age (years) & & & & 0.567 \\
\hline$<50$ & 25 & 11 & 14 & \\
\hline$\geq 50$ & 55 & 28 & 27 & \\
\hline Sex & & & & 0.476 \\
\hline Male & 46 & 24 & 22 & \\
\hline Female & 34 & 15 & 19 & \\
\hline Fuhrman grade & & & & 0.001 \\
\hline $\mathrm{I}+\mathrm{II}$ & 38 & 11 & 27 & \\
\hline $\mathrm{III}+\mathrm{IV}$ & 42 & 28 & 14 & \\
\hline Tumor-Node-Metastasis stage & & & & 0.009 \\
\hline $\mathrm{pT} 1+\mathrm{pT} 2$ & 42 & 13 & 29 & \\
\hline $\mathrm{pT} 3+\mathrm{pT} 4$ & 38 & 26 & 18 & \\
\hline Histological type & & & & 0.001 \\
\hline Clear cell & 43 & 13 & 30 & \\
\hline Papillary & 36 & 25 & 11 & \\
\hline Tumor diameter & & & & 0.001 \\
\hline$<4 \mathrm{~cm}$ & 36 & 10 & 26 & \\
\hline$\geq 4 \mathrm{~cm}$ & 44 & 29 & 15 & \\
\hline Venous invasion & & & & 0.002 \\
\hline Yes & 45 & 29 & 16 & \\
\hline No & 35 & 10 & 25 & \\
\hline
\end{tabular}

LOXL2, lysyl oxidase-like 2 .
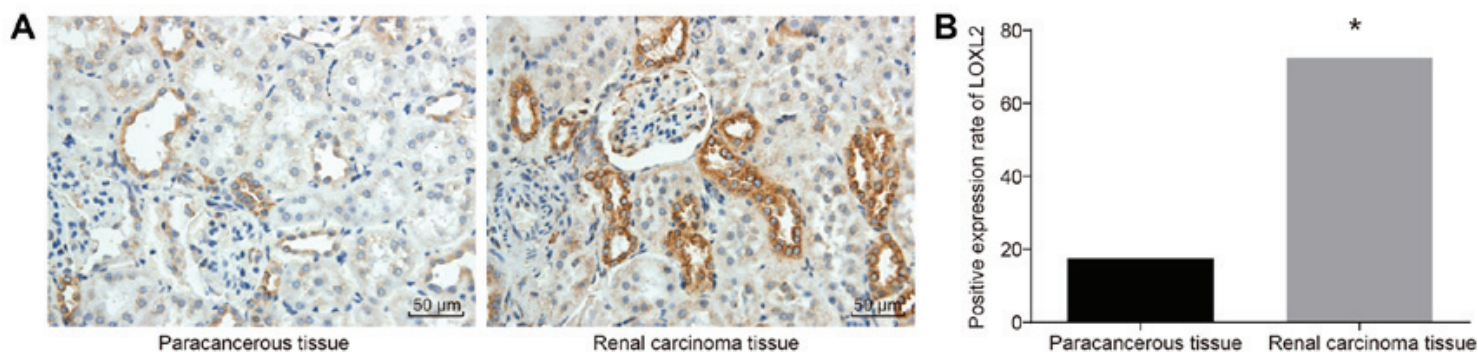

Figure 2. Immunohistochemistry results revealed that LOXL2 protein was highly expressed in RCC cells. (A) LOXL2-positive cells were located in the cytoplasm as indicated by brown-yellow granules (magnification, x200). (B) The protein expression rate of LOXL2 in RCC tissues was 72.5\% (58/80) and in adjacent normal tissues $17.5 \%$ (14/80); $\mathrm{n}=80$. A $\chi^{2}$ test was used for analysis. ${ }^{*} \mathrm{P}<0.05$ vs. adjacent normal tissues. LOXL2, lysyl oxidase-like 2 ; RCC, renal cell carcinoma.

in RCC tissues. Subsequently, RT-qPCR and western blot analysis were performed. The results (Fig. 3) demonstrated that, compared with the adjacent normal tissues, the mRNA expression levels of LOXL2, FAK, Src, MMP-9, N-cadherin and vimentin were significantly increased and the mRNA expression of E-cadherin was significantly decreased in RCC tissues (all $\mathrm{P}<0.05)$, whereas the protein expression levels of LOXL2, p-FAK/FAK, p-Src/Src, MMP-9, N-cadherin and vimentin were significantly increased and the protein expression of E-cadherin significantly decreased in RCC tissues (all $\mathrm{P}<0.05$ ). Taken together, these data indicate that genes involved in LOXL2 and FAK/Src signaling pathways are highly expressed in RCC, and EMT-associated gene expression may be affected in RCC tissues.

LOXL2 downregulation in 786-0 and Cak1 cells. In order to study the expression of LOXL2 in normal renal tubular epithelial cells (HK-2) and RCC cell lines, LOXL2 mRNA expression in HK-2, 786-O, ACHN, Caki1 and A498 cells was detected by RT-qPCR. Compared with HK-2 cells, the expression of LOXL2 mRNA in RCC cell lines was significantly increased $(\mathrm{P}<0.05$; with the highest expression 
A

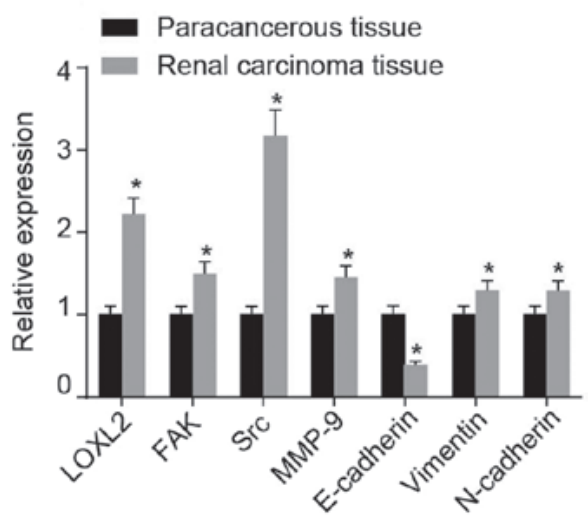

B

LOXL2

FAK $\cdots$

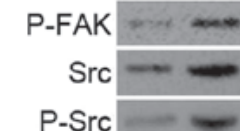

MMP-9 =

E-cadherin

Vimentin

$\mathrm{N}$-cadherin

GAPDH

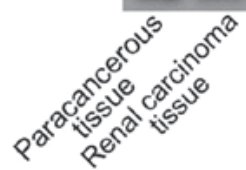

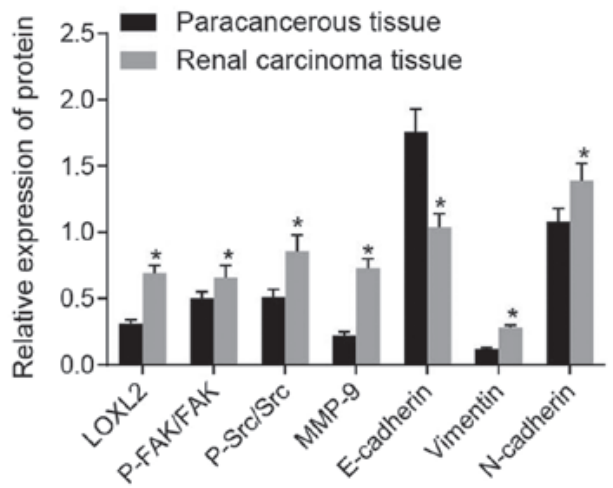

Figure 3. According to reverse transcription-quantitative polymerase chain reaction and western blot analysis, LOXL2 and FAK/Src signaling pathway-associated genes are highly expressed in RCC tissues, and genes associated with the epithelial-to-mesenchymal transition are affected. (A) mRNA expression of LOXL2, FAK, Src, MMP-9, N-cadherin and vimentin was increased in RCC tissues, whereas that of E-cadherin was decreased compared with adjacent normal tissues. (B) Protein expression of LOXL2, FAK, Src, MMP-9, N-cadherin and vimentin were increased in RCC tissues, whereas that of E-cadherin was decreased, in contrast to the adjacent normal tissues; $n=80$. (C) Quantified protein expression of LOXL2, FAK, P-FAK, Src, P-Src, MMP-9, E-cadherin, vimentin and N-cadherin. Paired t-test was used for analysis; ${ }^{\mathrm{P}}<0.05$ vs. adjacent normal tissues. LOXL2, lysyl oxidase-like 2; Src, steroid receptor coactivator; FAK, focal adhesion kinase; RCC, renal cell carcinoma; MMP, matrix metalloproteinase; P-, phosphorylated; N-cadherin, neuronal cadherin; E-cadherin, epithelial cadherin.
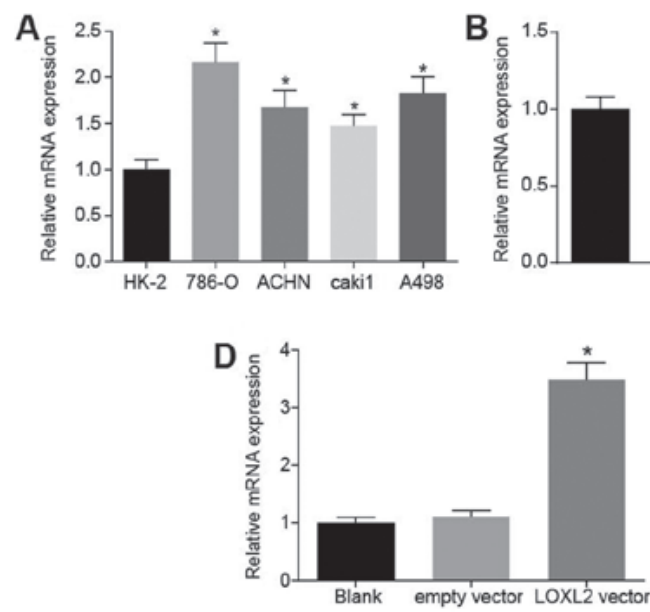

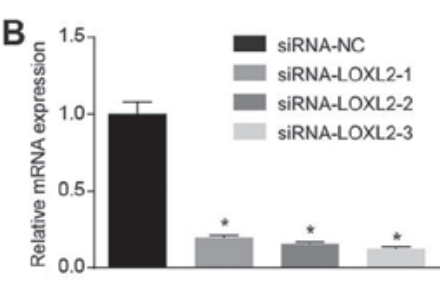

E

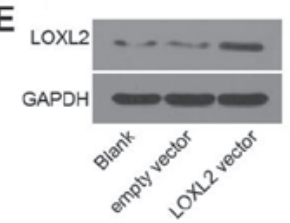

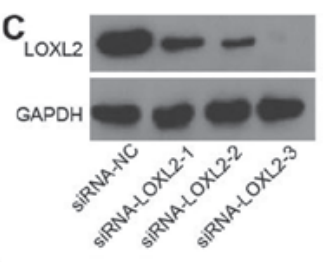
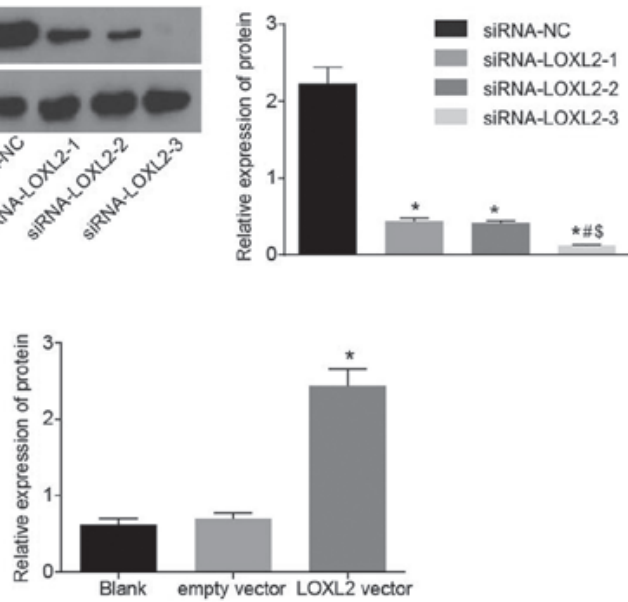

Figure 4. Screening results ensured that 786-O cells were selected for the siRNA experiment and Caki1 cells for the overexpression experiment. (A) mRNA expression of LOXL2 was the highest in 786-O cells and lowest in Cakil cells compared with all other renal cell carcinoma cell lines. "P<0.05 vs. HK-2 cells. (B) mRNA expression of LOXL2 was decreased (the siRNA-NC group was used as the control group). "P $<0.05$ vs. siRNA-NC group. (C) Protein band images of 786-O cells following transfection with the siRNA plasmid. " $\mathrm{P}<0.05$ vs. siRNA-NC group; ${ }^{\prime \prime} \mathrm{P}<0.05$ vs. the siRNA-LOXL2-1 group; ${ }^{\$} \mathrm{P}<0.05$ vs. the siRNA-LOXL2-2 group. (D) mRNA expression of LOXL2 was increased (the blank group was used as the control group). "P $<0.05$ vs. the blank group. (E) Protein band images of Caki1 cells following transfection with LOXL2 overexpression plasmid. One-way analysis of variance was used for comparison and the experiment was repeated three times. LOXL2, lysyl oxidase-like 2; NC, negative control; siRNA, small interfering RNA.

in 786-O cells and the lowest expression in Caki1 cells, compared with all other RCC cell lines; Fig. 4A). Thus, 786-O cells were selected for siRNA transfection experiments and Cakil cells for overexpression experiments. The efficiency detection results of each group following 786-O cell transfection with interference plasmids are presented in Fig. 4B. Compared with the siRNA-NC group, the siRNA-LOXL2-1, siRNA-LOXL2-2 and siRNA-LOXL2-3 groups exhibited significantly decreased LOXL2 mRNA expression $(\mathrm{P}<0.05$; Fig. 4B) and protein expression $(\mathrm{P}<0.05$; Fig. 4C). The lowest protein expression of LOXL2 was observed in the siRNA-LOXL2-3 group, with a significantly lower expression of LOXL2 compared with the other two siRNA groups $(\mathrm{P}<0.05)$, indicating that the siRNA-LOXL2-3 group had the highest interference efficiency. Therefore, the plasmid in the siRNA-LOXL2-3 group was selected for further experimentation. Following Cakil cell transfection with LOXL2 overexpression plasmids, the mRNA and protein expression of LOXL2 increased significantly compared with the blank control $(\mathrm{P}<0.05$; Fig. 4D and $\mathrm{E})$. Therefore, 786-O cells were selected for siRNA experiments and Cakil cells for overexpression experiments. 

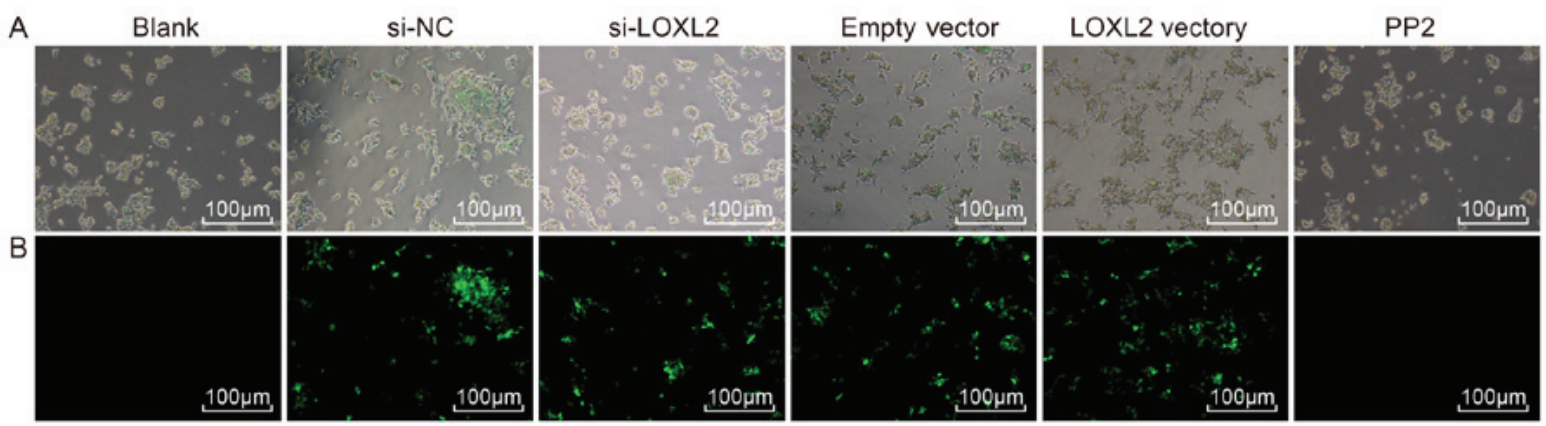

Figure 5. Adenovirus vector was successfully transfected (magnification, x100). (A) Observation of total RCC cells under an optical microscope. (B) A large quantity of green fluorescence was observed in the cells of the si-NC, si-LOXL2, empty vector and LOXL2 vector groups. LOXL2, lysyl oxidase-like 2; NC, negative control.

Transfection efficiency. Cell transfection was performed to measure green fluorescence in cells. Following cell transfection, no green fluorescence was observed in the normal, blank and PP2 groups under a fluorescence microscope. However, intense green fluorescence was observed in the cells of the si-NC, si-LOXL2, empty vector and LOXL2 vector groups (expression rate, $>80 \%$ ), indicating that the adenovirus vector was successfully transfected into the RCC cells and kidney tubular epithelial cells and effectively expressed in these cells (Fig. 5).

Silencing LOXL2 inhibits the activation of the FAK/SrC pathway and EMT in RCC cells. Next, RT-qPCR and western blot analysis were used to determine mRNA and protein expression of associated genes and proteins, respectively. As presented in Fig. 6, the results demonstrated that following the transfection of 786-O cells, the mRNA and protein expression of LOXL2, FAK, Src, MMP-9, N-cadherin and vimentin were significantly reduced and that of E-cadherin was significantly increased in the si-LOXL2 group compared with the blank and si-NC groups $(\mathrm{P}<0.05)$. Following the transfection of Cakil cells, the mRNA and protein expression of LOXL2, FAK, Src, MMP-9, $\mathrm{N}$-cadherin and vimentin were significantly increased and that of E-cadherin was significantly decreased in the LOXL2 vector group compared with the blank and empty vector groups (all $\mathrm{P}<0.05$; Fig. 6). In the PP2 group, gene expression changes exhibited the opposite trend compared with the LOXL2 vector group, except for LOXL2 which demonstrated a similar trend. In comparison with the cells in the LOXL2 vector group, the mRNA and protein expressions of p-FAK/FAK, p-Src/Src, MMP-9, N-cadherin and vimentin were significantly decreased, and that of E-cadherin was significantly increased in the LOXL2 vector + PP2 group (all $\mathrm{P}<0.05$; Fig. 6). The aforementioned data indicated that silencing LOXL2 inhibits the activation of the FAK/Src signaling pathway and of MMP-9 and EMT. Additionally, PP2, as a FAK/Src signaling pathway inhibitor, reversed the effect of LOXL2 vector on Caki1 cells. Consequently, activation of the FAK/Src pathway and EMT may be inhibited by silencing LOXL2 in RCC cells.

Silencing of LOXL2 inhibits the proliferation of RCC cells. Cell proliferation was assessed with an MTT assay and the results revealed differences in cell proliferation at 24, 48 and $72 \mathrm{~h}$ in each group. Compared with the cells in the blank and si-NC groups, the cell proliferation was significantly inhibited at all time points once 786-O cells were transfected with si-LOXL2 $(\mathrm{P}<0.05$; Fig. 7A). This indicates that the cell proliferation ability was repressed when LOXL2 expression was inhibited. In comparison with the cells in the blank and empty vector groups, once Caki1 cells were transfected with the LOXL2 vector, cell proliferation was significantly increased, while in the PP2 group it was significantly decreased ( $\mathrm{P}<0.05$; Fig. $7 \mathrm{~B})$. Additionally, the cell proliferation ability in the LOXL2 vector + PP2 group was significantly decreased compared with cells in the LOXL2 vector group ( $\mathrm{P}<0.05$; Fig. 7B). These data indicate that cell proliferation decreases when LOXL2 expression and the activation of the FAK/Src pathway are inhibited, and PP2 may reverse the effects of LOXL2 on the proliferation of RCC cells. In brief, silencing LOXL2 represses RCC cell proliferation.

Silencing LOXL2 inhibits the invasion of RCC cells. A Transwell assay was used to analyze the invasion of cells in each group. Compared with cells in the blank group, the number of invading cells was decreased significantly once 786-O cells were transfected with si-LOXL2 ( $<<0.05$; Fig. 8A and B). The results demonstrated that silencing LOXL2 inhibited the invasion of RCC cells. Compared with cells in the blank and empty vector groups, the number of invading cells was significantly increased once Cakil cells were transfected with LOXL2 vector $(\mathrm{P}<0.05)$, whereas that in the PP2 group was significantly decreased $(\mathrm{P}<0.05)$. In comparison with cells in the LOXL2 vector group, the number of invading cells in the LOXL2 vector + PP2 group was decreased significantly $(\mathrm{P}<0.05$; Fig. $8 \mathrm{C}$ and $\mathrm{D})$. The results revealed that cell invasion ability decreases when LOXL2 expression and the activation of the FAK/Src pathway are inhibited. In addition, PP2 is able to reverse the effects of LOXL2 on the invasion ability of RCC cells. In conclusion, LOXL2 silencing inhibits RCC cell invasion.

Silencing of LOXL2 inhibits the migration of RCC cells. A wound healing test was applied to detect cell migration. The results are presented in Fig. 9A and B. Once the 786-O cells were transfected with si-LOXL2, the cell migration ability was significantly weakened $(\mathrm{P}<0.05)$. Therefore, silencing 
A

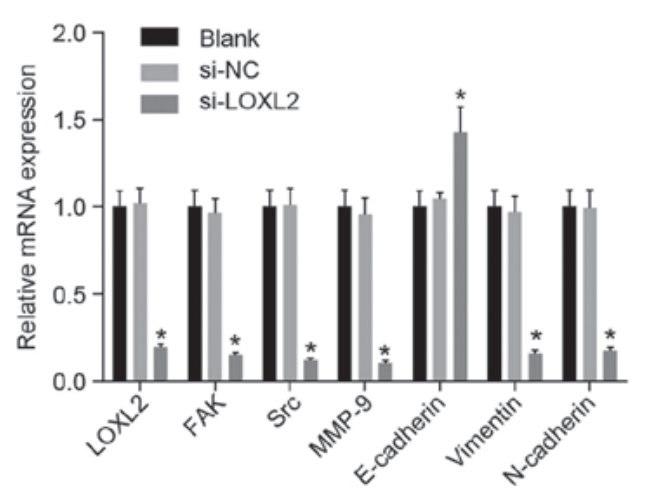

C $10 \times 12=-1$

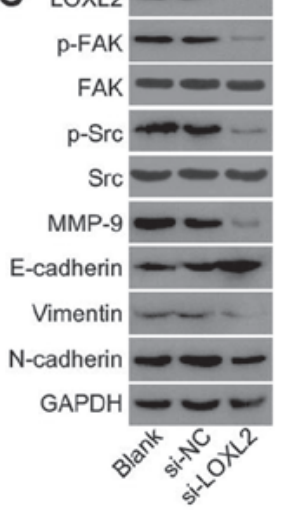

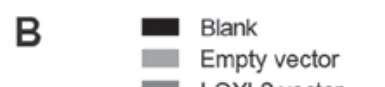
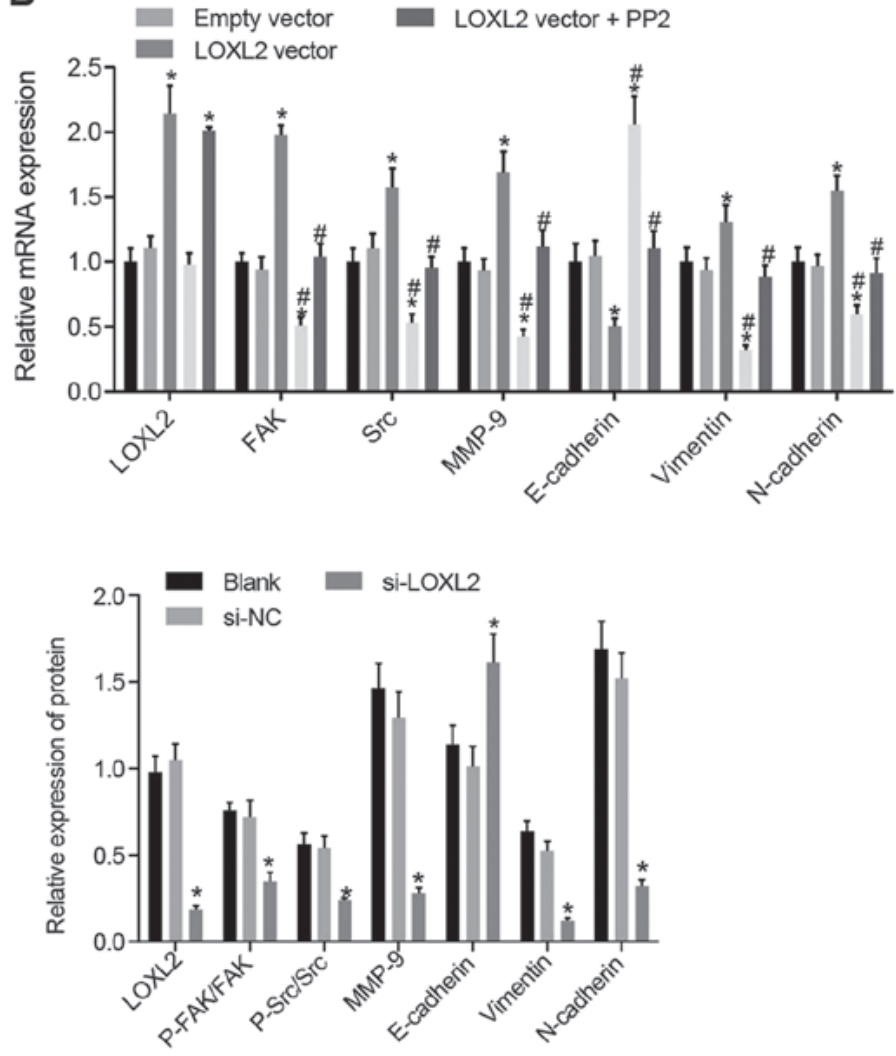

D

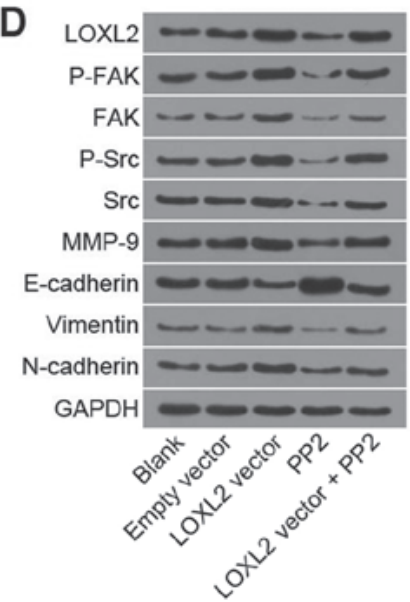

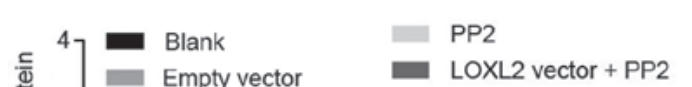

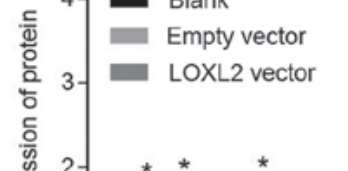

LOXL2 vector + PP2

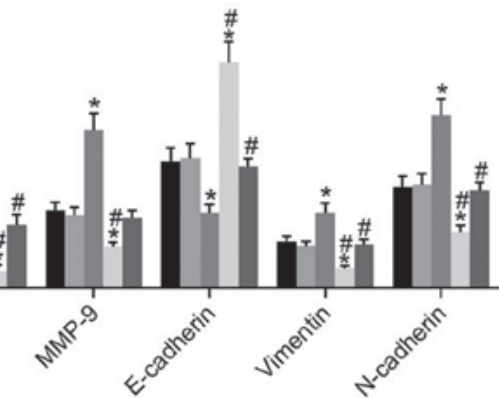

Figure 6. Silencing of LOXL2 inhibited activation of the FAK/Src pathway and affected factors associated with epithelial-to-mesenchymal transition. (A) Once 786-O cells were transfected with si-LOXL2, the mRNA expression of FAK, Src, MMP-9, N-cadherin and vimentin were significantly decreased and that of E-cadherin was significantly increased; " $\mathrm{P}<0.05$ vs. blank and si-NC groups. (B) Once Cakil cells were transfected with the LOXL2 vector, the mRNA expression of FAK, Src, MMP-9, N-cadherin and vimentin were significantly increased and that of E-cadherin was significantly decreased. In the PP2 group, mRNA expression changes exhibited the opposite trend. ${ }^{*} \mathrm{P}<0.05$ vs. the blank and empty vector groups; ${ }^{*} \mathrm{P}<0.05$ vs. the LOXL2 vector group. (C) Once 786-O cells were transfected with si-LOXL2, the protein expression of FAK, Src, MMP-9, N-cadherin and vimentin was significantly decreased and that of E-cadherin was significantly increased. "P $<0.05$ compared with the blank and si-NC groups. (D) Once Cakil cells were transfected with LOXL2 vector, the protein expressions of FAK, Src, MMP-9, N-cadherin and vimentin were significantly increased and that of E-cadherin was significantly decreased. In the PP2 group, protein expression changes exhibited the opposite trend. ${ }^{*} \mathrm{P}<0.05$ vs. the blank and empty vector groups; ${ }^{*} \mathrm{P}<0.05$ vs. the LOXL2 vector group. One-way analysis of variance was used for comparison and the experiment was repeated three times. LOXL2, lysyl oxidase-like 2; Src, steroid receptor coactivator; FAK, focal adhesion kinase; MMP, matrix metalloproteinase; NC, negative control; P-, phosphorylated; si-, small interfering RNA; N-cadherin, neuronal cadherin; E-cadherin, epithelial cadherin.

LOXL2 may inhibit the migration of RCC cells. By contrast, once Cakil cells were transfected with LOXL2 vector, cell migration ability was enhanced significantly compared with cells in the blank and empty vector groups $(\mathrm{P}<0.05)$, whereas the cell migration ability in the PP2 and PP2 + LXOL2 vector groups was significantly reduced (both $\mathrm{P}<0.05$ ). Compared with cells in the LOXL2 vector group, the cell migration ability in the LOXL2 vector + PP2 group was significantly decreased $(\mathrm{P}<0.05$; Fig. 9C and $\mathrm{D})$. The results demonstrated that inhibition of LOXL2 expression and inactivation of the FAK/Src pathway inhibited the migration of RCC cells, and PP2 was able to reverse the effects of LOXL2 on cell 

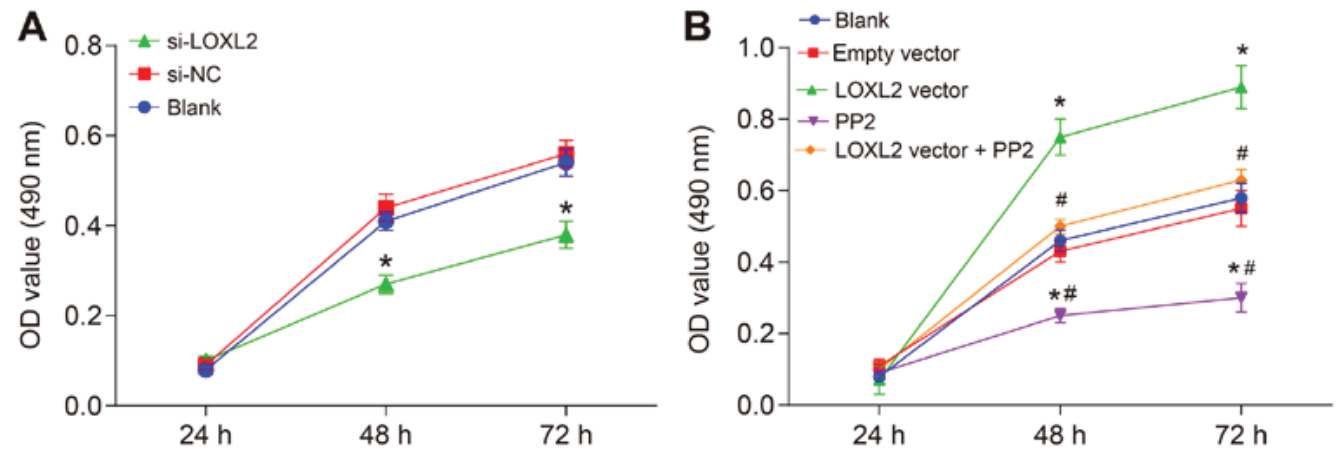

Figure 7. According to the MTT assay, silencing of LOXL2 inhibited the proliferation of renal cell carcinoma cells. (A) Cell proliferation curve following transfection of 786-O cells. ${ }^{*} \mathrm{P}<0.05$ vs. the blank and si-NC groups. (B) Cell proliferation curve following transfection of Cakil cells. ${ }^{*} \mathrm{P}<0.05$ vs. the blank and empty vector groups; ${ }^{\mathrm{P}} \mathrm{P}<0.05$ vs. LOXL2 vector group. One-way analysis of variance was used for comparison and the experiment was repeated three times. LOXL2, lysyl oxidase-like 2; NC, negative control; si-, small interfering RNA; OD, optical density.

A

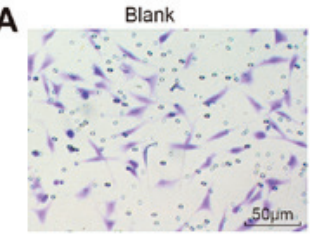

C

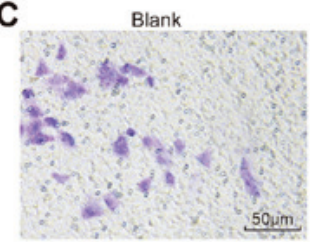

$$
\text { PP2 }
$$

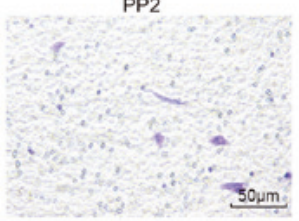

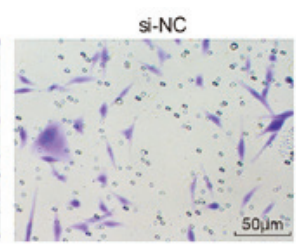
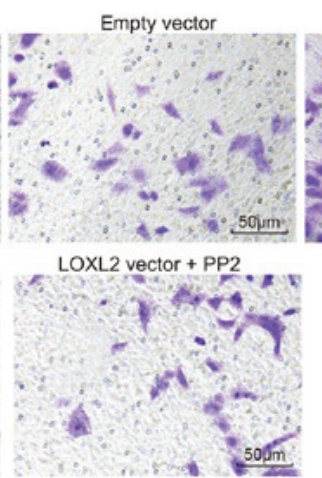

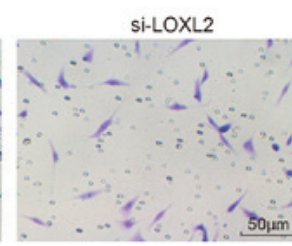

LOXL2 vector

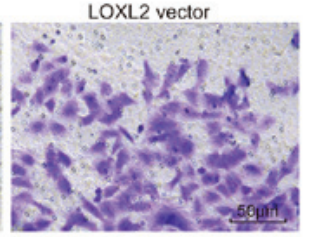

D
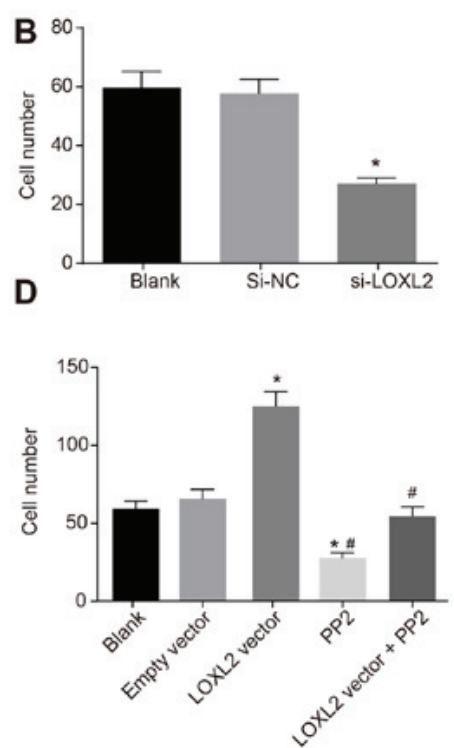

Figure 8. Based on the data of the Transwell assay, silencing LOXL2 may suppress renal cell carcinoma cell invasion. (A) The number of 786-O cells invading the basolateral chamber was significantly reduced. (B) Quantified number of invaded cells. ${ }^{*} \mathrm{P}<0.05$ vs. the blank and si-NC groups. (C) The number of Caki1 cells invading the basolateral chamber was significantly increased. (D) Quantified number of invaded cells. * $<<0.05$ vs. the blank and empty vector groups; ${ }^{\#} \mathrm{P}<0.05$ vs. the LOXL2 vector group. One-way analysis of variance was used for comparison and the experiment was repeated three times. LOXL2, lysyl oxidase-like 2; NC, negative control; si-, small interfering RNA.

migration. In conclusion, the experimental data indicate that the migration of RCC cells may be suppressed by LOXL2 silencing.

Silencing of LOXL2 inhibits the cell cycle distribution and promotes the apoptosis of RCC cells. The cell cycle detection of RCC cells was performed by flow cytometry (Fig. 10A and B). The results demonstrated that, compared with cells in the blank group, once 786-O cells were transfected with si-LOXL2, there were a significantly higher number of cells at the G1 phase, and a significantly lower number in the $\mathrm{S}$ and $\mathrm{G} 2 / \mathrm{M}$ phases $(\mathrm{P}<0.05)$, indicating that silencing LOXL2 may inhibit cell cycle distribution in RCC cells. In comparison with cells in the blank and empty vector groups, once Caki1 cells were transfected with LOXL2 vector, a significantly fewer number of cells were arrested at the G1 phase and a significantly greater number of cells were arrested at the $S$ and $\mathrm{G} 2 / \mathrm{M}$ phases (all $\mathrm{P}<0.05)$. The number of cells at the $\mathrm{G} 1$ phase increased significantly, and decreased significantly at the S and G2/M phases, in the PP2 group compared with the blank, empty vector and LOXL2 vector groups (all $\mathrm{P}<0.05$ ). Compared with cells in the LOXL2 vector group, in the LOXL2 vector + PP2 group, a significantly greater number of cells were arrested at the G1 phase and significantly fewer cells at the $\mathrm{S}$ and $\mathrm{G} 2 / \mathrm{M}$ phases (all $\mathrm{P}<0.05$; Fig. 10C and D), indicating that suppression of LOXL2 expression and inactivation of the FAK/Src pathway may reduce the percentage of RCC cells at the S phase.

Apoptosis of RCC cells was assessed by flow cytometry. The results indicated that, compared with cells in the blank group, once 786-O cells were transfected with si-LOXL2, cell apoptosis increased significantly $(\mathrm{P}<0.05$; Fig. 10E and $\mathrm{F})$. Once Caki1 cells were transfected with the LOXL2 vector, cell apoptosis was significantly decreased $(\mathrm{P}<0.05)$, whereas that in the PP2 and PP2 + LOXL2 vector groups was significantly increased $(\mathrm{P}<0.05)$ compared with the blank and empty vector groups. Additionally, compared with cells 
A
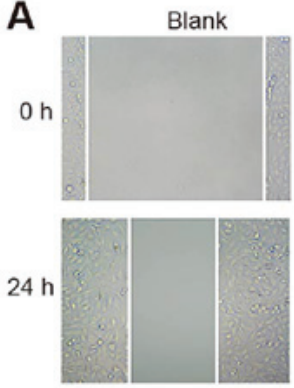

C
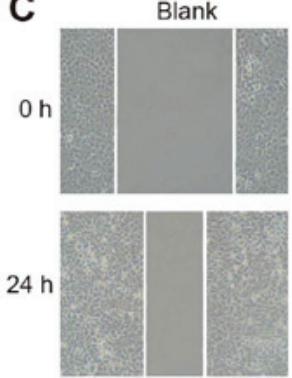

PP2
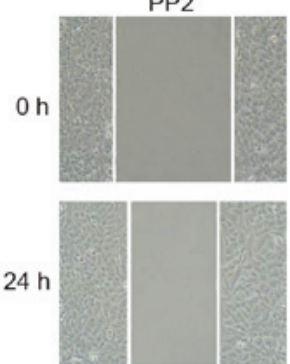

si-NC
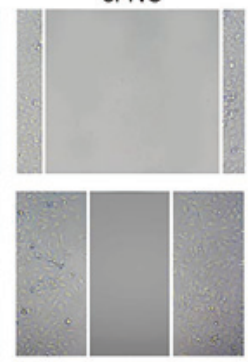

Empty vector

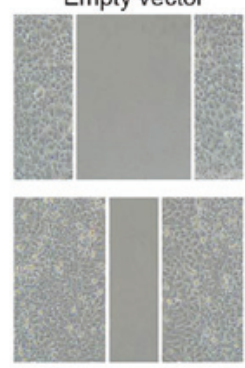

LOXL2 vector + PP2

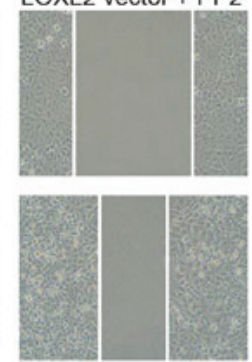

Si-LOXL2

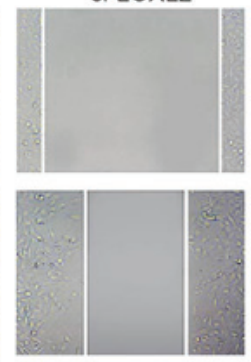

LOXL2 vector

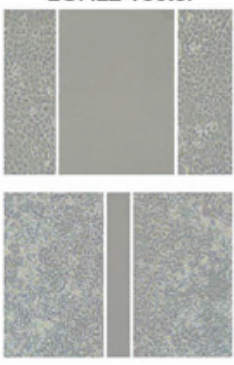

B

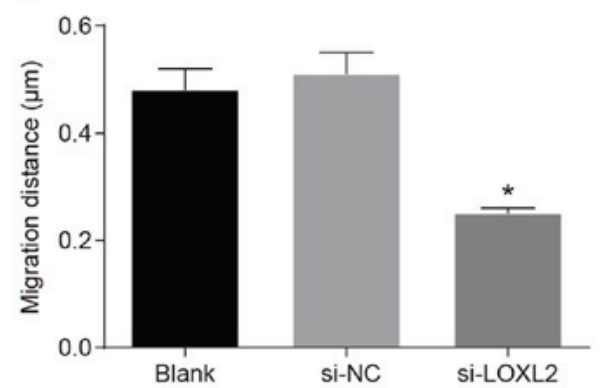

D

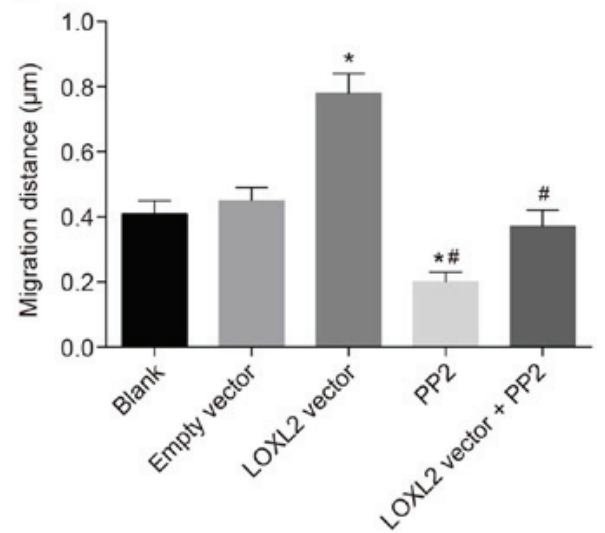

Figure 9. Silencing LOXL2 may suppress renal cell carcinoma cell migration according to the scratch test. (A) Once 786-O cells were transfected with si-LOXL2, the number of migrating cells was reduced. (B) Quantified migration distance of the cells. * $\mathrm{P}<0.05$ vs. the blank and si-NC groups. (C) The number of migrating cells was increased once Caki1 cells were transfected with LOXL2 vector. (D) Quantified migration distance of the cells. *P<0.05 vs. the blank and empty vector groups; ${ }^{\mathrm{P}}<0.05 \mathrm{vs}$. the LOXL2 vector group. One-way analysis of variance was used for comparison and the experiment was repeated three times. LOXL2, lysyl oxidase-like 2; NC, negative control; si-, small interfering RNA.

in the LOXL2 vector group, cell apoptosis in the LOXL2 vector + PP2 group was significantly increased (Fig. 10G and $\mathrm{H})$. These data suggest that, if the LOXL2 expression and activation of the FAK/Src pathway are inhibited, the apoptosis of RCC cells is promoted. Therefore, PP2 reverses the effect of LOXL2 on RCC cell apoptosis. In conclusion, LOXL2 silencing inhibits the cell cycle distribution and promotes the apoptosis of RCC cells.

\section{Discussion}

RCC is commonly a fatal malignancy due to late diagnosis and poor treatment options (21). The aim of the present study was to investigate the effects and potential mechanisms of action of LOXL2 on the EMT and proliferation and invasion of RCC cells through the Src/FAK signaling pathway.

The results demonstrated that the expression of LOXL2 in RCC tissues was increased compared with that in adjacent normal tissues. The expression of LOXL2 was detected in renal tissue and in tubular epithelial cells in human kidneys, and LOXL2 functions as a promoter for the progression of tubulointerstitial fibrosis (22). A previous study reported that, in comparison with adjacent non-cancerous renal tissues, LOXL2 was substantially elevated in specimens of human clear cell RCC (23). Furthermore, the expression of LOX in the kidney was revealed to be markedly elevated in hyperuricemia, which is associated with renal diseases (24).

According to the results of the clinicopathological characteristics analysis, LOXL2 expression was revealed to be associated with tumor grade, stage (Fuhrman and TNM), type, diameter and venous invasion. The expression of LOXL2 was increased in patients with tumor grade III-IV, a tumor diameter $\geq 4 \mathrm{~cm}$ and venous invasion. RCC staging is mainly based on the TNM staging system, which, together with tumor grade, provides necessary information regarding treatment and prognosis (25). At the time of symptomatic diagnosis, 30-40\% of patients with RCC will have already developed metastasis to the lymph nodes or other organs (4). Although patients with RCC have a 5 -year survival rate of $85 \%, \sim 1 / 3$ of patients are diagnosed with a metastatic or advanced stage of the disease, with a 5-year survival rate of $10 \%$ (26). A previous study reported that high LOX protein expression was associated with the occurrence and number of lymph node metastases (27). In addition, the high expression of LOXL2 has been reported to be associated with the poor prognosis of patients with colon cancer, and it may be applied in clinical practice for risk classification (28).

The Src/FAK signaling pathway-associated genes FAK and Src exhibited increased expression in RCC cells compared with 

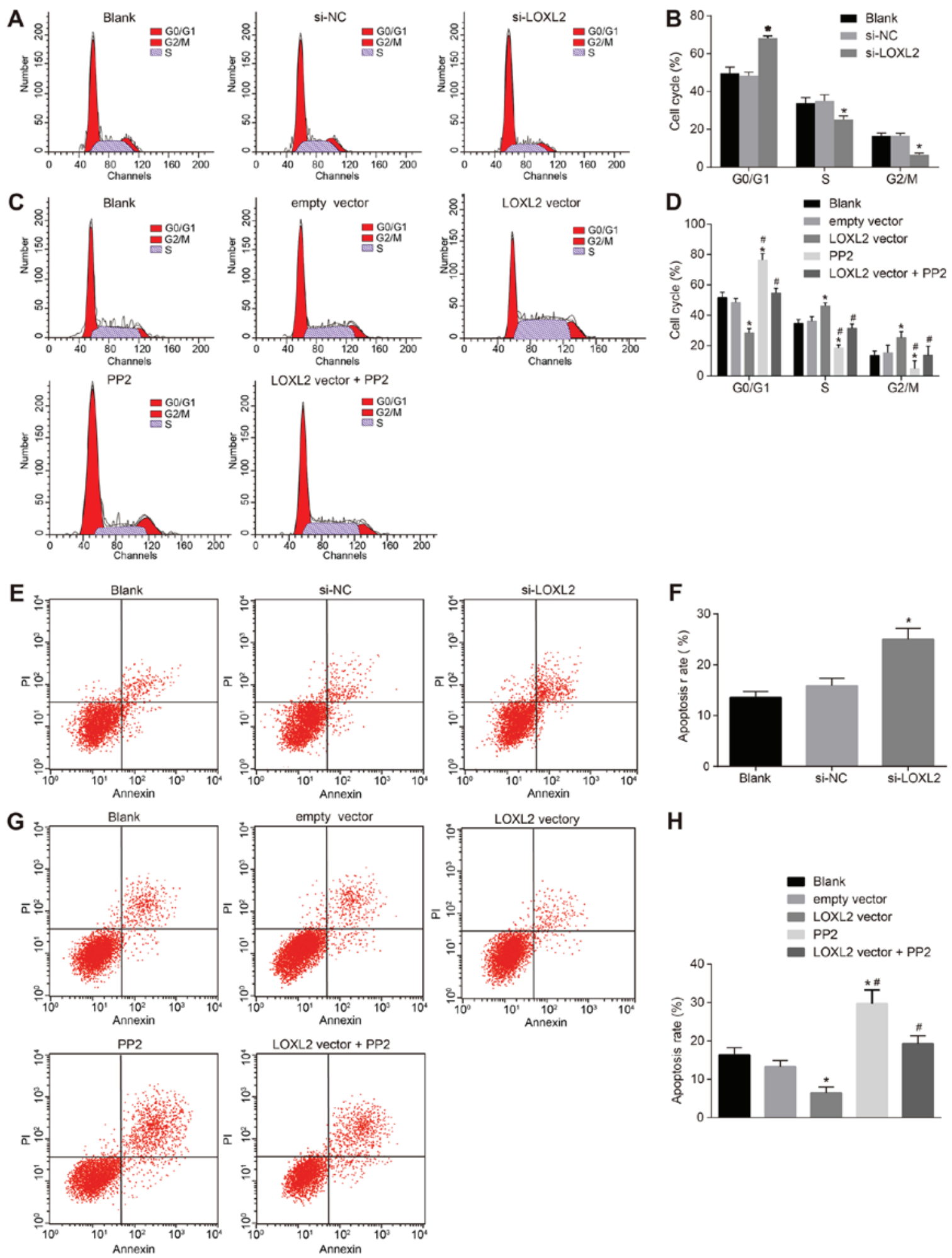

H

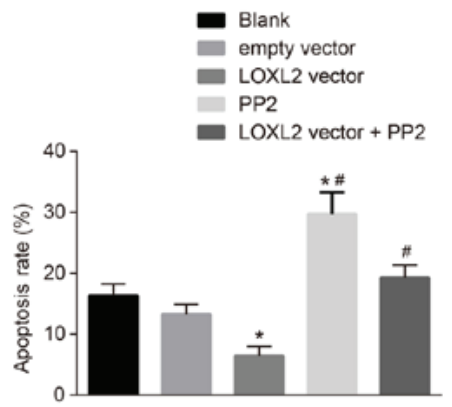

Figure 10. Flow cytometry revealed that renal cell carcinoma cell cycle distribution was inhibited and apoptosis was promoted following the silencing of LOXL2. (A) Once 786-O cells were transfected with si-LOXL2, the number of cells at the S phase was significantly decreased. (B) Quantified number of cells at each stage of the cell cycle. "P $<0.05$ vs. the blank and si-NC groups. (C) The number of cells at the $\mathrm{S}$ phase was significantly increased once Cakil cells were transfected with LOXL2 vector. (D) Quantified number of cells at each stage of the cell cycle. ${ }^{\prime \prime} \mathrm{P}<0.05$ vs. the blank and empty vector groups; ${ }^{\prime} \mathrm{P}<0.05$ vs. the LOXL2 vector group. (E) 786-O cell apoptosis was significantly enhanced once 786-O cells were transfected with si-LOXL2. (F) Quantified apoptotic rate. ${ }^{*} \mathrm{P}<0.05$ vs. the blank and si-NC groups. (G) Cakil cell apoptosis was significantly decreased once Cakil cells were transfected with LOXL2 vector. (H) Quantified apoptotic rate. ${ }^{*} \mathrm{P}<0.05$ vs. the blank and empty vector groups; ${ }^{*} \mathrm{P}<0.05$ vs. the LOXL2 vector group. One-way analysis of variance was used for comparison and the experiment was repeated three times. LOXL2, lysyl oxidase-like 2; NC, negative control; si-, small interfering RNA.

in normal renal tubular epithelial cells. Src is a non-receptor tyrosine kinase that serves a key role in regulating multiple cellular functions, including cell proliferation, adhesion and survival (29), whereas FAK participates in tumor cell 
migration and metastasis (30). The mRNA expression of Src was high in RCC samples compared with that in normal kidney samples, and Src may promote the occurrence of malignant phenotypes of RCC due to the resistance to apoptosis induced by B-cell lymphoma-extra large and angiogenesis by Src/signal transducer and activator of transcription 3 (STAT3)/vascular endothelial growth factor signaling (31). FAK has been detected in adult RCC tissues, and it is has also been hypothesized to be involved in pediatric renal tumor types through affecting cell survival (32).

A key result of the present study was that, compared with the blank group, the expression of FAK, Src, MMP-9, $\mathrm{N}$-cadherin and vimentin was substantially decreased in the si-LOXL2 and PP2 groups, while the expression of E-cadherin was notably increased, indicating that the silencing of LOXL2 may inactivate the Src/FAK signaling pathway and inhibit EMT. LOXL2, through biochemical and biomechanical mechanisms, is capable of stimulating tumor development, potentially by activating a diverse range of signaling pathways (12). According to a previous report, secreted LOXL2 and LOXL4 were revealed to regulate the Src/FAK signaling pathway in gastric cancer $(33,34)$. LOX may also affect colorectal cancer by mechanisms involving Src and FAK $(35,36)$. MMP-9 serves a pivotal role in tumor angiogenesis, cell invasion and migration, in addition to EMT regulation $(37,38)$. EMT is generally considered to participate in cancer progression and metastasis (39). N-cadherin is considered to be the mesenchymal marker in the process of EMT; E-cadherin loss and vimentin gain are two crucial steps in EMT $(40,41)$. LOXL2 promotes invasion by regulating the expression and activity of the extracellular protein tissue inhibitor of MMP-9 (42). Furthermore, accumulating evidence indicates that LOXL2 downregulates E-cadherin expression and stimulates EMT (43). The Src/FAK signaling pathway may also participate in the EMT of thyroid cancer cells (44). LOXL2 in breast cancer cells has been demonstrated to activate oncogenic signaling pathways, resulting in EMT by extracellular in addition to intracellular mechanisms (45). Therefore, it has been hypothesized that LOXL2 silencing may inhibit EMT in RCC cells via downregulating the Src/FAK signaling pathway.

Another notable observation of the present study was that silencing of LOXL2 inhibits RCC cell migration and invasion though the inactivation of the Src/FAK signaling pathway. The inactivation of the Src/STAT3 signaling pathway may induce apoptosis of human renal carcinoma Cakil cells (46). FAK/Src signaling serves a crucial role in the invasion of neoplastic cells (47). LOXL2, a member of an amine oxidase family, has been suggested to be implicated in cross-link formation in stromal collagens and elastin, cell motility, and tumor formation and progression (48). The inhibition of LOXL2 substantially inhibits cancer cell migration and invasion in RCC (49). LOXL2 expression in stromal fibroblasts was also revealed to be associated with the depth of tumor invasion, lymphatic and venous invasion, in addition to peritoneal dissemination in gastric cancer (50).

In conclusion, the results of the present study indicated that LOXL2 silencing inhibits the EMT, proliferation and invasion of RCC cells through the Src/FAK signaling pathway, which may provide a novel approach to the treatment of
RCC. However, the specific mechanisms have yet to be fully elucidated and the sample size of the present study was limited; therefore, further investigation is required.

\section{Acknowledgements}

Not applicable.

\section{Funding}

Not applicable.

\section{Availability of data and materials}

The analysed data sets generated during the study are available from the corresponding author on reasonable request.

\section{Authors' contributions}

XH conceived the study and XH and JJY designed the study. JJY was involved in data collection. XH performed the statistical analysis and preparation of figures. $\mathrm{XH}$ drafted the paper. JJY contributed substantially to its revision. All authors read and approved the final manuscript.

\section{Ethics approval and consent to participate}

The study protocol was approved by the Ethics Committee of Shanghai Jiao Tong University Affiliated Sixth People's Hospital and Shanghai Jiao Tong University Affiliated Sixth People's Hospital South Campus, and all the patients signed informed consent forms. This study obtained the approval of the Ethics Review Committee of the Ethics Committee of Shanghai Jiao Tong University Affiliated Sixth People's Hospital and Shanghai Jiao Tong University Affiliated Sixth People's Hospital South Campus (approval no. 201407004).

\section{Patient consent for publication}

Not applicable.

\section{Competing interests}

The authors declare that they have no competing interests.

\section{References}

1. Linehan WM, Srinivasan R and Schmidt LS: The genetic basis of kidney cancer: A metabolic disease. Nat Rev Urol 7: 277-285, 2010.

2. Tan HJ, Norton EC, Ye Z, Hafez KS, Gore JL and Miller DC: Long-term survival following partial vs radical nephrectomy among older patients with early-stage kidney cancer. JAMA 307: 1629-1635, 2012.

3. Gohara A, Eltaki N, Sabry D, Murtagh D Jr, Jankun J, Selman SH and Skrzypczak-Jankun E: Human 5-, 12- and 15-lipoxygenase-1 coexist in kidney but show opposite trends and their balance changes in cancer. Oncol Rep 28: 1275-1282, 2012.

4. Morrissey JJ, London AN, Luo J and Kharasch ED: Urinary biomarkers for the early diagnosis of kidney cancer. Mayo Clin Proc 85: 413-421, 2010.

5. Yu SS, Quinn DI and Dorff TB: Clinical use of cabozantinib in the treatment of advanced kidney cancer: Efficacy, safety, and patient selection. OncoTargets Ther 9: 5825-5837, 2016. 
6. Chow WH, Dong LM and Devesa SS: Epidemiology and risk factors for kidney cancer. Nat Rev Urol 7: 245-257, 2010.

7. Jonasch E: Incorporating New Systemic Therapies in Kidney Cancer Treatment. J Natl Compr Canc Netw 15 (5S): 703-705, 2017.

8. Dent P, Curiel DT and Fisher PB: The potential of virus-based gene therapies for treatment of metastatic kidney cancer. Expert Rev Anticancer Ther 11: 809-811, 2011.

9. Froger L, Neuzillet $\mathrm{Y}$ and Lebret T: Indications for ablative treatment in kidney cancer in the elderly. Prog Urol 22 1004-1009, 2012 (In French)

10. Jaganjac S, Schefe L, Avdagić E, Spahović H and Hiros M: Preoperative kidney tumor embolization as procedure for therapy of advanced kidney cancer. Acta Inform Med 22: 302-305, 2014

11. Kim YM, Kim EC and Kim Y: The human lysyl oxidase-like 2 protein functions as an amine oxidase toward collagen and elastin. Mol Biol Rep 38: 145-149, 2011.

12. $\mathrm{Wu} \mathrm{L}$ and $\mathrm{Zhu} \mathrm{Y}$ : The function and mechanisms of action of LOXL2 in cancer (Review). Int J Mol Med 36: 1200-1204, 2015

13. Nishikawa R, Chiyomaru T, Enokida H, Inoguchi S, Ishihara T, Matsushita R, Goto Y, Fukumoto I, Nakagawa M and Seki N: Tumour-suppressive microRNA-29s directly regulate LOXL2 expression and inhibit cancer cell migration and invasion in renal cell carcinoma. FEBS Lett 589: 2136-2145, 2015

14. Lu D, Yao Q, Zhan C, Le-Meng Z, Liu H, Cai Y, Tu C, Li X, Zou Y and Zhang S: MicroRNA-146a promote cell migration and invasion in human colorectal cancer via carboxypeptidase M/src-FAK pathway. Oncotarget 8: 22674-22684, 2017.

15. Suwaki N, Vanhecke E, Atkins KM, Graf M, Swabey K Huang P, Schraml P, Moch H, Cassidy AM, Brewer D, et al: A HIF-regulated VHL-PTP1B-Src signaling axis identifies a therapeutic target in renal cell carcinoma. Sci Transl Med 3: 85ra47, 2011.

16. Barker HE, Bird D, Lang G and Erler JT: Tumor-secreted LOXL2 activates fibroblasts through FAK signaling. Mol Cancer Res 11: 1425-1436, 2013

17. Kim BR, Dong SM, Seo SH, Lee JH, Lee JM, Lee SH and Rho SB: Lysyl oxidase-like 2(LOXL2) controls tumor-associated cell proliferation through the interaction with MARCKSL1. Cell Signal 26: 1765-1773, 2014.

18. Deckers IA, Schouten LJ, Van Neste L, van Vlodrop IJ, Soetekouw PM, Baldewijns MM, Jeschke J, A huja N, Herman JG, van den Brandt PA, et al: Promoter methylation of cdol identifies clear-cell renal cell cancer patients with poor survival outcome. Clin Cancer Res 21: 3492-3500, 2015.

19. Brookman-May SD, May M, Wolff I, Zigeuner R, Hutterer GC Cindolo L, Schips L, De Cobelli O, Rocco B, De Nunzio C, et al; CORONA Project; European Association of Urology (EAU) Young Academic Urologists (YAU) Renal Cancer Group: Evaluation of the prognostic significance of perirenal fat invasion and tumor size in patients with pT1-pT3a localized renal cell carcinoma in a comprehensive multicenter study of the CORONA project. Can we improve prognostic discrimination for patients with stage pT3a tumors? Eur Urol 67 943-951, 2015

20. Kotsopoulos J, Zhang S, Akbari M, Salmena L, Llacuachaqui M, Zeligs M, Sun P and Narod SA: BRCA1 mRNA levels following a 4-6-week intervention with oral 3,3'-diindolylmethane. Br J Cancer 111: 1269-1274, 2014

21. Mickley A, Kovaleva O, Kzhyshkowska J and Gratchev A: Molecular and immunologic markers of kidney cancer-potentia applications in predictive, preventive and personalized medicine. EPMA J 6: 20, 2015

22. Choi SE, Jeon N, Choi HY, Shin JI, Jeong HJ and Lim BJ: Lysyl oxidase like 2 is expressed in kidney tissue and is associated with the progression of tubulointerstitial fibrosis. Mol Med Rep 16: 2477-2482, 2017

23. Hase H, Jingushi K, Ueda Y, Kitae K, Egawa H, Ohshio I, Kawakami R, Kashiwagi Y, Tsukada Y, Kobayashi T, et al: LOXL2 status correlates with tumor stage and regulates integrin levels to promote tumor progression in ccRCC. Mol Cancer Res 12: 1807-1817, 2014.

24. Yang Z, Xiaohua W, Lei J, Ruoyun T, Mingxia X, Weichun H, Li F, Ping W and Junwei Y: Uric acid increases fibronectin synthesis through upregulation of lysyl oxidase expression in rat renal tubular epithelial cells. Am J Physiol Renal Physiol 299: F336-F346, 2010.

25. Fiore DC and Fox CL: Urology and nephrology update: Bladder and kidney cancer. FP Essent 416: 26-29, 2014
26. Bianchi L, Rossi L, Tomao F, Papa A, Zoratto F and Tomao S Thyroid dysfunction and tyrosine kinase inhibitors in renal cell carcinoma. Endocr Relat Cancer 20: R233-R245, 2013.

27. Sakai M, Kato H, Sano A, Tanaka N, Inose T, Kimura H, Sohda M, Nakajima M and Kuwano H: Expression of lysyl oxidase is correlated with lymph node metastasis and poor prognosis in esophageal squamous cell carcinoma. Ann Surg Oncol 16: 2494-2501, 2009.

28. Torres S, Garcia-Palmero I, Herrera M, Bartolomé RA, Peña C, Fernandez-Aceñero MJ, Padilla G, Peláez-García A, Lopez-Lucendo M, Rodriguez-Merlo R, et al: LOXL2 Is Highly Expressed in Cancer-Associated Fibroblasts and Associates to Poor Colon Cancer Survival. Clin Cancer Res 21: 4892-4902, 2015.

29. Chojnacka K and Mruk DD: The Src non-receptor tyrosine kinase paradigm: New insights into mammalian Sertoli cell biology. Mol Cell Endocrinol 415: 133-142, 2015.

30. Pei G, Lan Y, Chen D, Ji L and Hua ZC: FAK regulates E-cadherin expression via p-SrcY416/p-ERK1/2/p-Stat3Y705 and PPAR $\gamma / \mathrm{miR}-125 \mathrm{~b} / \mathrm{Stat} 3$ signaling pathway in B16F10 melanoma cells. Oncotarget 8: 13898-13908, 2017.

31. Majid S, Saini S, Dar AA, Hirata H, Shahryari V, Tanaka Y, Yamamura S, Ueno K, Zaman MS, Singh K, et al: MicroRNA-205 inhibits Src-mediated oncogenic pathways in renal cancer. Cancer Res 71: 2611-2621, 2011.

32. Megison ML, Gillory LA, Stewart JE, Nabers HC, Mrozcek-Musulman E and Beierle EA: FAK inhibition abrogates the malignant phenotype in aggressive pediatric renal tumors. Mol Cancer Res 12: 514-526, 2014

33. Peng L, Ran YL, Hu H, Yu L, Liu Q, Zhou Z, Sun YM, Sun LC, Pan J, Sun LX, et al: Secreted LOXL2 is a novel therapeutic target that promotes gastric cancer metastasis via the Src/FAK pathway. Carcinogenesis 30: 1660-1669, 2009.

34. Li RK, Zhao WY, Fang F, Zhuang C, Zhang XX, Yang XM, Jiang SH, Kong FZ, Tu L, Zhang WM, et al: Lysyl oxidase-like 4 (LOXL4) promotes proliferation and metastasis of gastric cancer via FAK/Src pathway. J Cancer Res Clin Oncol 141: 269-281, 2015.

35. Baker AM, Cox TR, Bird D, Lang G, Murray GI, Sun XF, Southall SM, Wilson JR and Erler JT: The role of lysyl oxidase in SRC-dependent proliferation and metastasis of colorectal cancer. J Natl Cancer Inst 103: 407-424, 2011.

36. Baker AM, Bird D, Lang G, Cox TR and Erler JT: Lysyl oxidase enzymatic function increases stiffness to drive colorectal cancer progression through FAK. Oncogene 32: 1863-1868, 2013.

37. Raghu H, Sodadasu PK, Malla RR, Gondi CS, Estes N and Rao JS: Localization of uPAR and MMP-9 in lipid rafts is critical for migration, invasion and angiogenesis in human breast cancer cells. BMC Cancer 10: 647, 2010

38. Asuthkar S, Nalla AK, Gondi CS, Dinh DH, Gujrati M, Mohanam S and Rao JS: Gadd45a sensitizes medulloblastoma cells to irradiation and suppresses MMP-9-mediated EMT. Neuro-oncol 13: 1059-1073, 2011.

39. Iwatsuki M, Mimori K, Yokobori T, Ishi H, Beppu T, Nakamori S, Baba $\mathrm{H}$ and Mori M: Epithelial-mesenchymal transition in cancer development and its clinical significance. Cancer Sci 101: 293-299, 2010.

40. Zeng T, Peng L, Chao C, Fu B, Wang G, Wang Y and Zhu X: miR-451 inhibits invasion and proliferation of bladder cancer by regulating EMT. Int J Clin Exp Pathol 7: 7653-7662, 2014.

41. Myong NH: Loss of E-cadherin and Acquisition of Vimentin in Epithelial-Mesenchymal Transition are Noble Indicators of Uterine Cervix Cancer Progression. Korean J Pathol 46: 341-348, 2012.

42. Barker HE, Chang J, Cox TR, Lang G, Bird D, Nicolau M, Evans HR, Gartland A and Erler JT: LOXL2-mediated matrix remodeling in metastasis and mammary gland involution. Cancer Res 71: 1561-1572, 2011.

43. Park JS, Lee JH, Lee YS, Kim JK, Dong SM and Yoon DS Emerging role of LOXL2 in the promotion of pancreas cancer metastasis. Oncotarget 7: 42539-42552, 2016.

44. Baquero P, Jiménez-Mora E, Santos A, Lasa M and Chiloeches A: TGF $\beta$ induces epithelial-mesenchymal transition of thyroid cancer cells by both the BRAF/MEK/ERK and Src/FAK pathways. Mol Carcinog 55: 1639-1654, 2016.

45. Moon HJ, Finney J, Xu L, Moore D, Welch DR and Mure M: MCF-7 cells expressing nuclear associated lysyl oxidase-like 2 (LOXL2) exhibit an epithelial-to-mesenchymal transition (EMT) phenotype and are highly invasive in vitro. J Biol Chem 288: 30000-30008, 2013. 
46. Park JE, Park B, Chae IG, Kim DH, Kundu J, Kundu JK and Chun KS: [Corrigendum] Carnosic acid induces apoptosis through inactivation of Src/STAT3 signaling pathway in human renal carcinoma Caki cells. Oncol Rep 36: 3717 , 2016.

47. Tai G, Hohenstein P and Davies JA: FAK-Src signalling is important to renal collecting duct morphogenesis: Discovery using a hierarchical screening technique. Biol Open 2: 416-423, 2013.

48. Zhan P, Shen XK, Qian Q, Zhu JP, Zhang Y, Xie HY, Xu CH Hao KK, Hu W, Xia N, et al: Down-regulation of lysyl oxidase-like 2 (LOXL2) is associated with disease progression in lung adenocarcinomas. Med Oncol 29: 648-655, 2012.
49. Kurozumi A, Kato M, Goto Y, Matsushita R, Nishikawa R, Okato A, Fukumoto I, Ichikawa T and Seki N: Regulation of the collagen cross-linking enzymes LOXL2 and PLOD2 by tumor-suppressive microRNA-26a/b in renal cell carcinoma. Int J Oncol 48: 1837-1846, 2016.

50. Kasashima H, Yashiro M, Kinoshita H, Fukuoka T, Morisaki T, Masuda G, Sakurai K, Kubo N, Ohira M and Hirakawa K: Lysyl oxidase-like 2 (LOXL2) from stromal fibroblasts stimulates the progression of gastric cancer. Cancer Lett 354: 438-446, 2014.

cc) (i) $\Theta$ This work is licensed under a Creative Commons Attribution-NonCommercial-NoDerivatives 4.0 International (CC BY-NC-ND 4.0) License. 